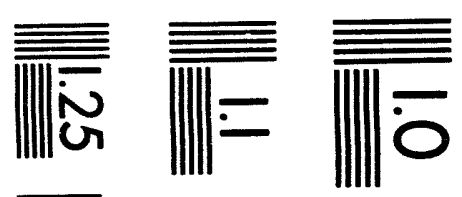

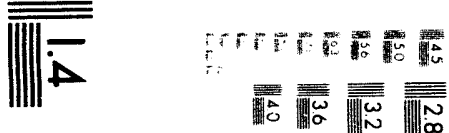

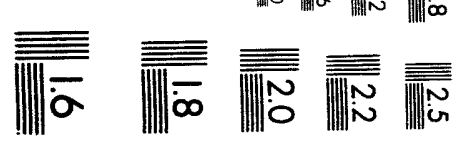



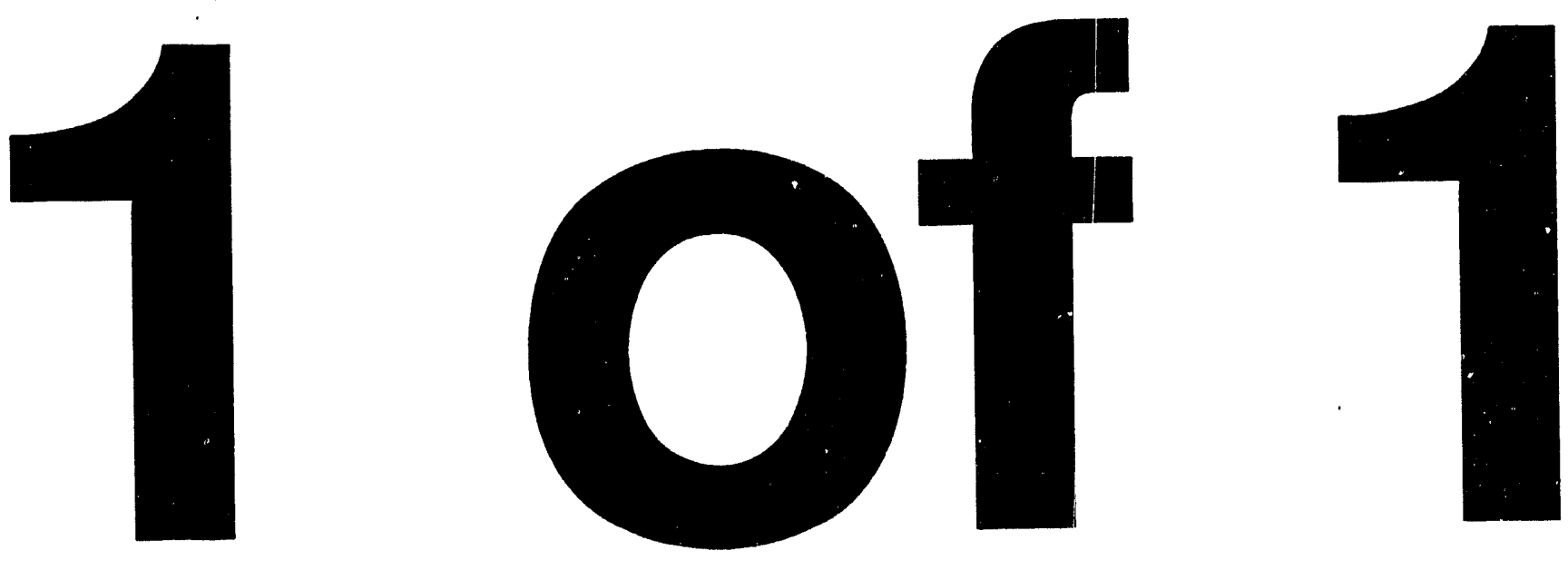
NRTSC

NUCLEAR REACTOR TECHNOLOGY

AND SCIENTIFIC COMPUTATIONS

WSRC-TR-93-406

RETENTION :

PERMANENT

\title{
STABILITY OF FORCED-CONVECTION SUBCOOLED BOILING IN STEADY-STATE AND TRANSIENT ANNULAR FLOW (U)
}

\author{
by \\ VOLKER GEHRKE, S. G. BANKOFF
}

ISSUED: JUNE, 1993

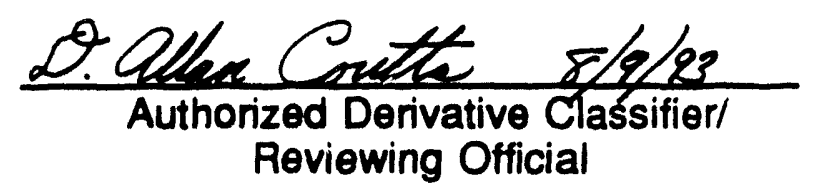

SRTC SAVANNAH RIVER TECHNOLOGY CENTER, AIKEN, SC 29808 Westinghouse Savannah River Corporation

Prepared for the U.S. Department of Energy under Contract DE-AC09-89SR18035

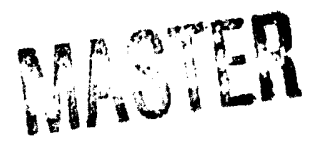


Document:

Title:

Contract:

Task title:
WSRC-TR-93-406

STABILITY OF FORCED-CONVECTION SUBCOOLED BOILING IN STEADY-STATE AND TRANSIENT ANNULAR FLOW (U)

AX 811457

Approvals

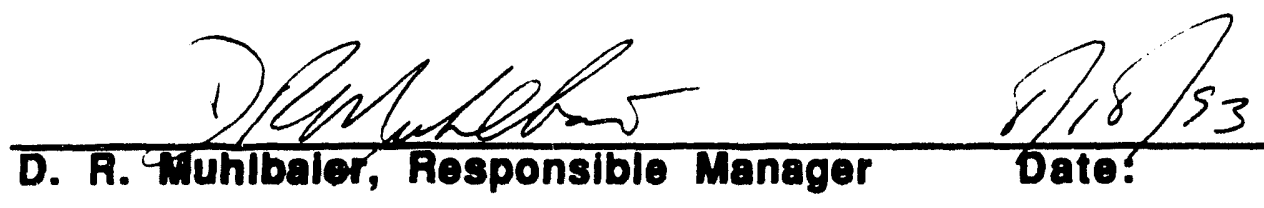

A' Manet

A. J. Garrett, Level 3 Manager
$8 / 18 / 93$ Date: 


\section{DISCLAIMER}

This report was prepared as an account of work sponsored by an agency of the United States Government. Neither the United States Government nor any agency thereof, nor any of their employees, makes any warranty, express or implied, or assumes any legal liability or responsibility for the accuracy, completeness, or usefulness of any information, apparatus, product, or process disclosed, or represents that its use would not infringe privately owned rights. Reference herein to any specific commercial product, process, or service by trade name, trademark, manufacturer, or otherwise does not necessarily constitute or imply its endorsement, recommendation, or favoring by the United States Government or any agency thereof. The views and opinions of authors expressed herein do not necessarily state or reflect those of the United States Government or any agency thereof.

This report has been reproduced directly from the best available copy.

Available to DOE and DOE contractors from the Office of Scientific and Technical Information, P. O. Box 62 , Oak Ridge, TN 37831 ; prices available - Im (615) $576-8401$.

Available to the public from the National Technical Information Service, U. S. Department of Commerce, 5285 Port Royal Rd., Springfield, VA 22161. 
SRTC Perspective

D. A. Coutts

Senior Engineer

The coolant in the Savannah River Site (SRS) production nuclear reactor assemblies is circulated as a subcooled liquid under normal operating conditions. This coolant is evenly distributed throughout multiple annular flow channels with a uniform pressure profile across each coolant flow channel. During the postulated Loss of Coolant Accident (LOCA), which is initiated by a hypothetical guillotine pipe break, the coolant flow though the reactor assemblies is significantly reduced. The flow reduction and accompanying power reduction (after shutdown is initiated) occur in the first 1 to 2 seconds of the LOCA. This portion of the LOCA is referred to as the flow instability (FI) phase (1).

The reactor assemblies are subject to a type of FI known as a Ledinegg flow excursion. This type of instability is common in low pressure subcooled flow channels that exhibit a demand curve with a negative sloped region and a relative maximum and minimum as shown in Figure 1. The relative minimum is the result of the flow acceleration created by the change in fluid density, and an increase in the frictional pressure loss created by vapor nucleating on the heater surface and effectively increasing the flow channel roughness. The postulated LOCA can initiate such a flow excursion.

Assembly power limits are calculated for LOCA conditions using the FLOWTRAN-FI code. The code calculates a dimensionless ratio known as the Stanton number at each axial position in the channel through the course of the transient. This Stanton number was introduced by Saha and Zuber (2) to describe the onset of significant void (OSV) in channels where subcooled nucleate boiling is present.

$$
S t=\frac{\phi}{G c_{p}\left(T_{\text {sat }}-T_{b}\right)}
$$

where:

$$
\begin{aligned}
& \phi \quad=\text { local heat flux } \\
& G \quad=\text { mass velocity } \\
& C_{p}=\text { liquid specific heat } \\
& T_{\text {sat }}=\text { saturation temperature } \\
& T_{b}=\text { bulk liquid temperature }
\end{aligned}
$$

The Stanton number will vary both with time and position in the assembly. The reactor operating power is limited to preclude Stanton numbers in excess of 0.00455 during the LOCA. This value is 70 percent of the 0.065 value proposed by Saha and Zuber (2). This difference is a safety margin that accounts for data and calculation uncertainties.

OSV and the Stanton number criterion are steady-state concepts. It is desirable to know the uncertainties associated with their application to a transient process. The Experimental Thermal-Hydraulics Group of the Nuclear Engineering Section contracted SGB Associates of Evanston, IL to study the transient FI process. This work has been completed. Table 1 presents a summary of the reports produced during this study. 


\section{References}

1. Action Plan to Upgrade Thermal-Hydraulic Limits for Savannah River Site Production Reactors (U). 30 June 1989. WSRC-RP-89-373.

2. Saha, P., and N. Zuber, 1974, Point of Net Vapor Generation and Vapor oid Fraction in Subcooled Boiling. In Proceedings of the 5th International, leat Transfer Conference, Tokyo, Japan, September 3-7, 1974, 175-79. 


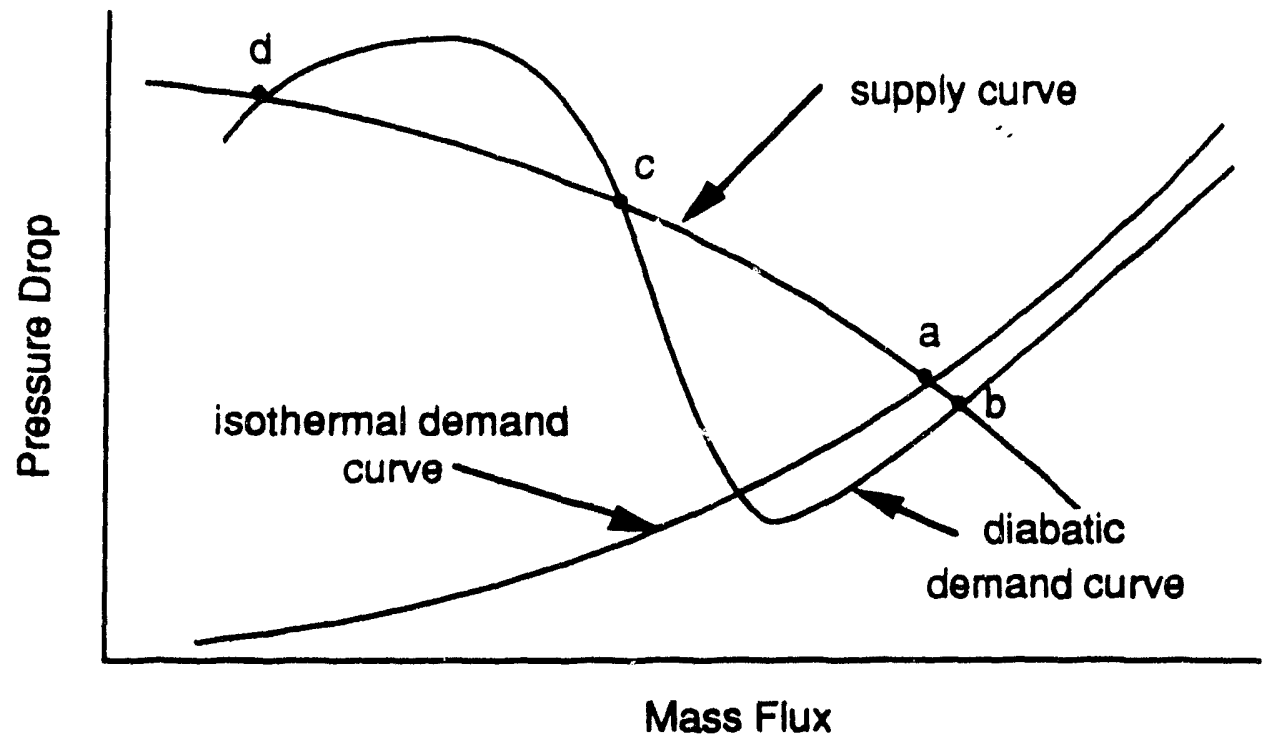

Figure 1. Demand curves for subcooled isothermal and diabatic systems

Table 1--Reports prepared as part of AX-1811457

\begin{tabular}{|c|c|c|}
\hline Authors & $\begin{array}{r}\text { Title } \\
\end{array}$ & Document number \\
\hline $\begin{array}{l}\text { Bankoff, S. G., S. C. Lee, } \\
\text { \& A. Knaani }\end{array}$ & $\begin{array}{l}\text { Literature Review on Forced- } \\
\text { Convection Subcooled Boiling }\end{array}$ & WSRC-TR-91-98 \\
\hline $\begin{array}{l}\text { Lee, S. C., \& S. G. } \\
\text { Bankoff }\end{array}$ & $\begin{array}{l}\text { Stability of Forced Convection } \\
\text { Subcooled Boiling }\end{array}$ & WSRC-TR-92-233 \\
\hline $\begin{array}{l}\text { Dorra, H., S. C. Lee, and } \\
\text { S. G. Bankoff }\end{array}$ & $\begin{array}{l}\text { A Critical Review of Predictive Models } \\
\text { for the Onset of Significant Void in } \\
\text { Forced-Convection Subcooled Boiling }\end{array}$ & WSRC-TR-93-404 \\
\hline $\begin{array}{l}\text { Lee, S. C., and S. G. } \\
\text { Bankoff }\end{array}$ & $\begin{array}{l}\text { Prediction of the Onset of Significant } \\
\text { Void in Transient Subcooled Flow } \\
\text { Boiling }\end{array}$ & WSAC-TR-93-405 \\
\hline $\begin{array}{l}\text { Gehrke, Volker, \& S. G. } \\
\text { Bankoff }\end{array}$ & $\begin{array}{l}\text { Stability of Forced-Convection } \\
\text { Subcooled Boiling in Steady-State and } \\
\text { Transient Annular Flow }\end{array}$ & WSRC-TR-93-406 \\
\hline $\begin{array}{l}\text { Dorra, H., S. C. Lee, and } \\
\text { S. G. Bankoff }\end{array}$ & $\begin{array}{l}\text { Onset of Significant Void in Internal } \\
\text { Flow, Forced Convection, Subcooled } \\
\text { Boiling }\end{array}$ & WSRC-TR-93-407 \\
\hline
\end{tabular}




\title{
Stability of Forced-Convection Subcooled Boiling in Steady-State and Transient Annular Flow
}

\author{
Volker Gehrke \\ and S. G. Bankoff \\ SGB Associates
}

1500 Oak St.

Evanston. Illinois. 60201

Mav 26, 1993 


\section{Contents}

1 Introduction 1

2 Description of the Model 1

2.1 Basic Concept . . . . . . . . . . . . . . . . . . . . . 2

2.2 OSV Criterion . . . . . . . . . . . . . . . . 3

2.3 Single-Phase Flow Model . . . . . . . . . . . . . 6

2.4 Limitations . . . . . . . . . . . . . . . . . . 9

3 Computational Performance 10

3.1 Basic Units of the Program . . . . . . . . . . . . . 10

3.2 Numerical Methods . . . . . . . . . . . . . . . . 10

3.3 Error Margins . . . . . . . . . . . . . . . . . . . 12

4 Steady State Flow Application $\quad 13$

4.1 Computational Results . . . . . . . . . . . . . . . . 13

4.2 Expcriments performed at Columbia University . . . . . . . . 14

4.2.1 The Design of the Steady State Experiments . . . . . . 14

4.2 .2 Comparison with the model . . . . . . . . . . . 14

5 Transient Flow Application $\quad 16$

5.1 Analysis of the Flow Transient . . . . . . . . . . . 16

5.1.1 Velocity Profiles................ 16

5.1 .2 Temperature Profiles ............... 17

5.2 OFI Prediction During the Transient . . . . . . . . . . 19

5.3 Experiments performed at Columbia University . . . . . . . 19

5.3.1 Design of the Transient Experiments . . . . . . . 19

5.3.2 Comparison With the Model . . . . . . . . . 20 
6 Conclusions

Notation

References

28

Tables

31

Figures

34 


\begin{abstract}
A semi-analytical model developed by Lee and Bankoff for OFI in round tubes is extended to annular or parallel-plate flows with unequal heat fluxes, and shown to compare well with data by Dougherty, et al. and by Whittle and Forgan. The model is a better fit in the high Peclet number range than the Saha-Zuber model, and is simple to use.
\end{abstract}




\section{Introduction}

The present study of OFI focuses on the conditions of low pressure and high velocity flow, present in the pressurized water reactors operated by Westinghouse Savannah River Company. The objective of this study is to provide a semi-analytical OSV model which not only improves the OFI predictions, especially for these conditions, but also has the capability to deal with various flow channel shapes and heat flux arrangements, and gives insight into OFI prediction in transient flows, as in a reactor trip. A literature review has been made of forced-convection subcooled boiling by Bankoff, et al. [3], previous models for OSV have been reviewed and have been compared with extensive data by Dorra, et al. [6] and a mechanistic model for OSV and a new model of OFI has been developed and adjusted to the experimental clata by calculations for a symmetrical flow between two flat plates by Lee and Bankoff [12]. The model is essentially based on the OSV criteria suggested by Levy [13] and Staub [19]. a single-phase flow model established by Kawamura [10] and the experimental data of of Whittle and Forgan [21] and Dougherty, et al. [i].

This report contains the investigation of an annular flow with various heat flux arrangements for steady state and transient flow. focusing on the experiments conducted by the Columbia University Heat Transfer Research Pacility at the request of Westinghouse Savannah River Company (1990). The objectives are to assess the influence of the inner and outer tube ratio, $r_{i} / r_{0}$, and of nonsymmetrical heating conditions on OFI and to compare the present model with recent anriular OFI experiments. Transient effects on the OFI prediction, based on the model and also the transient experiments, are also discussed.

\section{Description of the Model}

The present model for the OFI prediction of forced convection subcooled boiling is designed for the following specifications:

(a) Vertical downwards turbulent annular flow

(b) Prescribed pressure drop 
(c) Prescribed uniform heat flux for each tube ranging from 0.5 to $3 \mathrm{MW} / \mathrm{m}^{2}$

(d) Prescribed inlet uniform liquid temperature

(e) Hydrodynamically fully-developed flow in the heated section

(f) Hydraulic diameter ranging from 2 to $30 \mathrm{~mm}$.

(g) Mass velocity ranging from 1000 to $10000 \mathrm{~kg} / \mathrm{m}^{2} \mathrm{~s}$.

(h) Prescribed absolute pressure at the end of the heated section ranging from 1 to 5 bar.

(i) Inlet water temperature ranging from 25 to $50^{\circ} \mathrm{C}$.

The limits for the heat flux, the hydraulic diameter, the mass velocity, the absolute pressure and the inlet temperatures reflect the experimental data. to which the empirical constants of the model were adjusted.

\subsection{Basic Concept}

Experimental evidence $[\pi, 9,21]$ indicates that OFI for a flow with a pressuredriven boundary condition occurs very close to OSV. Hence, the prediction of OFI in the present model becomes the problem of predicting OSV.

OSV is defined as the transition from partially to fully-developed subcooled nucleate boiling, as indicated by a rapid increase in void fraction. Prior to OSV, the vapor generated remains completely as discrete bubbles attached to the heating surface. After OSV some bubbles detach from the surface, condensing slowly as they move through the subcooled liquid, and thus leading to a higher void fraction. Phenomenologically, OSV may be described as the point of the first departure of vapor bubbles from the surface or as the point of destabilization of the bubble layer at the wall. Hence. following Levy [13], a force balance for a bubble in single-phase flow is used as the central idea in the present model to establish the OFI criterion. He proposed that the local thermal conditions close to the heated surface must allow an isolated single bubble to reach a size where the forces parallel to surface attempting to remove the bubble from the surface exceed the forces holding the bubble to the surface. The present model distinguishes from previous similar models by mainly three features. 
1. All previous models performed analyses for the bulk flow, while using empirical correlations for the heat transfer coefficient (e.g. DittusBoelter equation [5]), the temperature distribution (e.g. Martinelli (14]), the friction factor and and the velocity distribution. The present model performs a one-dimensional analysis for the velocity and a twodimensional analysis for the liquid temperature.

2. Most previous models have used drag forces derived for isolated bubbles in single-phase flow. The present model uses a drag force expression derived for a bubble, taking into account that the bubble is in reality a part of a bubble boundary layer on a solid wall in subcooled convective boiling.

3. The surface tension force. which is hard to determine analytically, is correlated with a large number of real-scale experiments, some of which just have recently been performed.

Since uniform heat flux is assumed. OSV will occur first at the end of the heated section. Hence, OFI prediction in the present model results in the application of the OSV criterion to the local thermal and hydrodynamical conditions at the end of the heated section.

\subsection{OSV Criterion}

The OSV criterion in its present form follows the work of Lee and Bankoff [12].

Of all forces known to act on the bubbles attached to wall in direction of the flow which are the drag, the surface tension force, the buoyancy, the liquid inertia force. the lift force, the exess pressure force and the thermocapillary force, only the drag, the surface tension force and the buoyancy are expected to be of importance for the bubble departure. These are the same as the forces which Levy considered. Thus, the force balance for a vertical downwards flow has the form

$$
F_{B}+F_{S}-F_{D}=0
$$

where $F_{B}$ represents the buovancy force, $F_{S}$ the surface tension force and $F_{D}$ the drag. 
The buoyancy force $F_{B}$ is calculated by

$$
F_{B}=C_{B}\left(\rho_{f}-\rho_{g}\right) g\left(\frac{4}{3} \pi R_{b}^{3}\right)
$$

where $C_{B}$ is a proportionality constant, which takes into account that the bubble attached to the wall is not spherical.

For the evaluation of the drag force, basically the approach by Staub [19] was taken. He assumed that the wall at OSV is well covered by a bubble layer. which has to transmit the complete shear stress exerted by the liquid on the bubble layer to the wall. Consequently, a single bubble has to transmit a force equal to the product of the wall shear stress and the area projected by the bubble on the wall. In turn, the wall shear stress for a turbulent flow is proportional to the pressure head of the bulk flow and the drag coefficient. Hence it follows

$$
F_{D}=C_{D}\left(\frac{1}{2} \rho_{f} u_{m}^{2}\right)\left(\pi R_{b}^{2}\right)
$$

The most apprupriate correlation for the drag coefficient of a bubbly boundary layer for forced-convection subcooled boiling for the purpose of OSV prediction was thought to be the theoretical model proposed by Avdeev [2]. With the help of Avdeev's result, the drag coefficient is determined by

$$
\begin{gathered}
C_{D}=\left[5.84+16.0 \log \left(0.93+0.065 \sqrt[4]{K^{\prime}}\right)\right]^{-2} \\
\text { with } K=\frac{\rho_{f} u_{m} C_{p f} d_{h}\left(T_{\text {sat }}-T_{f}\right)}{k_{f}\left(T_{w}-T_{\text {sat }}\right)}
\end{gathered}
$$

This approach for the drag force is probably the most important difference of the present OSV model from recent studies of this problem. Al-Hayes and Winterton [1] and Rogers, et al. [16, 17] chose an approach based on the turbulent drag of a single bubble, obtaining a drag force proportional to the projected area of the bubble facing the flow and the local pressure head. The early approach of Staub has not been further pursued, although it most likely describes the real physical situation at OSV better. which is a destabilization of the bubble layer by shear forces exerted by the core liquid rather than a single bubble departure phenomenon. Staub originally considered the influence of the bubble boundary layer on the drag by regarding the bubbles as apparent roughnesses on the solid wall. 
Since there is no analytical solution for the surface tension force as yet, it was assumed to be proportional to the surface tension and the contact diameter, which, in turn, was assumed to be proportional to the bubble diameter. Therefore, the relation for the surface tension is

$$
F_{S}=C_{S} \sigma\left(2 \pi R_{b}\right)
$$

The comparison of the entire OFI model to the data of Whittle and Forgan [21] and Dougherty, et al. [7] indicated that $C_{S}$ might be correlated by the relation

$$
C_{S}=4.8310^{-4}\left[\frac{u_{m}}{\sqrt[4]{\frac{g \sigma}{\rho_{f}}}}\right]^{1.28}
$$

Substituting ecuations (2), (3) and (5) into equation (1) yields the following solution for the critical detachment bubble radius

$$
\begin{gathered}
R_{b . c r t}=\frac{1}{2 K_{1}}\left[1-\sqrt{1-4 K_{1} K_{2}}\right] \\
\text { with } K_{1}=\frac{s}{3}\left(\frac{C_{B}}{C_{D}}\right)\left[\frac{\left(\rho_{f}-\rho_{g}\right) g}{\rho_{f} u_{m}^{2}}\right] \text { and } K_{2}=\left(\frac{C_{S}}{C_{D}}\right)\left[\frac{4 \sigma}{\rho_{f} u_{m}^{2}}\right]
\end{gathered}
$$

If $4 K_{1} K_{2}$ is much less than one, which physically means that the buoyancy force is negligibly small compared to the drag force and the surface tension force, equation (7) may be linearized for $4 K_{1}^{\prime} K_{2}$ around $R_{b}=0$ and what yields the following simple approximation for the critical bubble radius

$$
R_{b, \mathrm{CTI} t}=\left(\frac{C_{S}}{C_{D}}\right)\left(\frac{\sigma}{\rho_{f} u_{m}^{2}}\right)
$$

This approximation should be valid for the present specifications. This is not only indicated by considering $K_{1}$ and $K_{2}$, but also by the experiments, which show that there is no significant difference between upward and downwards flow in respect to the OSV prediction.

The temperature at the bubble tip is assumed to be equal to the saturation temperature, where the distance between the tip of the bubble attached to the wall and the wall is specified by the bubble diameter used for the bubble force balance. 
Hence, the OSV criterion is that the liquid temperature at a distance from any of the walls, which is given by twice $R_{b, c r i t}$ of equation (8), is equal to the saturation temperature

$$
\begin{gathered}
T\left(L,\left[r_{i}+2 R_{b, c r i t}\right], t\right) \geq T_{\text {sat }}, \text { or } \\
T\left(L,\left[r_{\circ}-2 R_{b, c r i t}\right], t\right) \geq T_{\text {sat }}
\end{gathered}
$$

For the evaluation of the OSV criterion (9) the fluid properties for the bulk flow temperature at the outlet are taken.

\subsection{Single-Phase Flow Model}

Essentially following Kawamura [10], the transient one-dimensional velocity calculations and the transient two-dimensional temperature calculations in the present model are performed using the concept of eddy viscosity and eddy thermal diffusity. Differing from the Kawamura solution. the eddy viscosity, the thermal diffusivity and the physical liquid properties are evaluated as time-dependent, in order to assure reliable transient results. However, the physical properties are assumed to be not a function of the location. They are evaluated for the average of the inlet and the outlet bulk temperature. For the specifications given, the momentum balance and the boundary and initial conditions. as functions of the velocity $u(r, t)$ and the temperature $T(x, r, t)$, have the form

$$
\begin{aligned}
& \frac{\partial u}{\partial t}=-\left.\frac{1}{\rho_{f}(t)} \frac{d p}{d x}\right|_{t}+\frac{1}{r} \frac{\partial}{\partial r}\left[r\left\{\nu(t)+\epsilon_{M}(r, t)\right\} \frac{\partial u}{\partial r}\right] \\
& \text { B.C.: } u\left(r_{i}, t\right)=u\left(r_{0}, t\right)=0 \\
& \text { I.C.: } u(r, 0)=u_{0}(r) \\
& \frac{\partial T}{\partial t}+u(r, t) \frac{\partial T}{\partial x}=\frac{1}{r} \frac{\partial}{\partial r}\left[r\left\{\alpha(t)+\epsilon_{H}(r, t)\right\} \frac{\partial T}{\partial r}\right] \\
& \text { B.C.: }\left.\quad \therefore(t) \frac{\partial T}{\partial r}\right|_{r=r_{i}}=-q_{i}(t) ;\left.\quad k_{f}(t) \frac{\partial T}{\partial r}\right|_{r=r_{0}}=q_{o}(t): \quad T(0, r, t)=T_{i n}(t) \\
& \text { I.C. : } \quad T(x, r, 0)=T_{0}(x, r)
\end{aligned}
$$


The quantities $\epsilon_{M}$ in equation (10) and $\epsilon_{H}$ in equation (11) represent the eddy viscosity and the eddy thermal diffusity, respectively. For the eddy viscosity, the model uses the correlation suggested by Reichardt [15], in a form modified by Wilson and Medwell [22], by multiplying the Reichardt expression for the eddy viscosity by the van Driest damping factor [8] to extend the validity of the model to regions close to the wall. Originally Reichardt established his correlation for a circular tube. The eddy viscosity expression was adjusted to the fully-developed annular flow by Wilson and Medwell [22] with the following equation.

$$
\epsilon_{M}(r, t)=\left\{\begin{array}{cc}
0.133\left(r_{m}-r_{i}\right) u_{i}^{*}(t)\left[\frac{1}{2}+\left(\frac{r_{m}-r}{r_{m}-r_{1}}\right)^{2}\right]\left[1-\left(\frac{r_{m}-r}{r_{m}-r_{1}}\right)^{2}\right] \\
{\left[1-\exp \left(-\frac{\left(r-r_{1}\right) u_{i}^{*}(t)}{t^{+} \nu(t)}\right)\right]} & \text { for } r_{i} \leq r \leq r_{m} \\
0.133\left(r_{0}-r_{m}\right) u_{0}^{*}(t)\left[\frac{1}{2}+\left(\frac{r-r_{m}}{r_{0}-r_{m}}\right)^{2}\right]\left[1-\left(\frac{r-r_{m}}{r_{0}-r_{m}}\right)^{2}\right] \\
{\left[1-\exp \left(-\frac{\left(r_{0}-r\right) u_{0}^{*}(t)}{t^{+} \nu(t)}\right)\right]} & \text { for } r_{m} \leq r \leq r_{0}
\end{array}\right.
$$

In equation (12) $r_{m}$ specifies the cylindrical surface at which the momentum flux is zero for the steady state. Its value is

$$
r_{m}=r_{0} \sqrt{\frac{1-r_{i} / r_{0}}{2 \ln \left(r_{0} / r_{1}\right)}}
$$

The quantities $u_{i}^{*}(t)$ and $u_{0}^{*}(t)$ represent the friction velocity at the inner wall and the outer wall, respectively. They are defined and evaluated by

$$
\begin{aligned}
& u_{i}^{*}(t)=\sqrt{\frac{-\tau_{r x}\left(r_{i}, t\right)}{\rho(t)}}=\left[\left.\nu(t) \frac{\partial u}{\partial r}\right|_{r=r_{1}}\right]^{\frac{1}{2}} \\
& u_{0}^{*}(t)=\sqrt{\frac{\tau_{r x}\left(r_{0}, t\right)}{\rho(t)}}=\left[-\left.\nu(t) \frac{\partial u}{\partial r}\right|_{r=r_{0}}\right]^{\frac{1}{2}}
\end{aligned}
$$

Differing from Kawamura, the thermal eddy diffusity in equation (11) is obtained by a simplified relation between the eddy viscosity and the eddy thermal diffusity, suggested by White [20]

$$
P r_{t}=\frac{\epsilon_{M}}{\epsilon_{H}} \simeq 0.9
$$


The damping constant of the van Driest damping factor in equation (12) was adjusted by Kawamura to experiments, which he performed for this purpose, such that the values for the steady-state heat transfer coefficient measured agreed with those he calculated numerically. He found

$$
A^{+}=40
$$

Introducing the following nondimensionless quantities

$$
X=\frac{x}{L} ; \quad R=\frac{r}{\frac{d_{h}}{2}} ; \quad \tau=\frac{t}{\frac{d_{h}^{2}}{4 \nu_{0}}} ; \quad U=\frac{u}{u_{m 0}} ; \quad \theta=\frac{T-T_{i n}}{T_{s a t}+T_{i n}} ; \quad P=\frac{p}{\frac{\rho / u_{m e}^{2}}{2}}
$$

the governing equations (10) and (11) can be converted into the following nondimensional form

$$
\begin{aligned}
& \frac{\partial U}{\partial \tau}=-\left.R e_{0} \frac{d_{h}}{S L} \frac{d P}{d X}\right|_{r}+\frac{1}{R} \frac{\partial}{\partial R}\left[R\left\{\frac{\nu(\tau)}{\nu_{0}}+\epsilon_{. M}^{+}(R, \tau)\right\} \frac{\partial U}{\partial R}\right] \\
& \text { B.C.: } \quad I^{\prime}\left(R_{i}, \tau\right)=I^{\prime}\left(R_{0}, \tau\right)=0 \\
& \text { I.C.: } \quad L^{\prime}(R .0)=I_{0}(R) \\
& \frac{\partial \theta}{\partial \tau}+R e_{d h, 0} \frac{d_{h}}{t L} L^{\prime}(R, \tau) \frac{\partial \theta}{\partial X}=\frac{1}{P r_{0}} \frac{1}{R} \frac{\partial}{\partial R}\left[R\left\{\frac{\alpha(\tau)}{\alpha_{0}}+\epsilon_{M}^{+}(R, \tau) \frac{P r_{0}}{P r_{t}}\right\} \frac{\partial \theta}{\partial R}\right] \\
& \text { B.C': }\left.\quad \frac{\partial \theta}{\partial r}\right|_{r=r_{1}}=-q_{i}^{+}(\tau) ;\left.\quad \frac{\partial \theta}{\partial r}\right|_{r=r_{0}}=q_{0}^{+}(t) ; \quad \theta(0, r, t)=\theta_{i n} \\
& \text { I.C. : } \quad \theta(x, r, 0)=\theta_{0}(x, r)
\end{aligned}
$$

where the initial Reynolds number. the dimensional eddy viscosity and the wall heat fluxes are taken as

$$
\begin{gathered}
\operatorname{Re}_{d h .0}=\frac{d_{h} u_{m 0}}{\nu_{0}} \\
\epsilon_{M}^{+}(\tau)=\frac{\epsilon_{M}(t(\tau))}{\nu_{0}} \\
q_{i}^{+}(\tau)=\frac{q_{i}(t(\tau)) d_{h}}{2 k_{f}(t(\tau))\left(T_{s a t}-T_{i n}\right)}: \quad q_{o}^{+}(\tau)=\frac{q_{o}(t(\tau)) d_{h}}{2 k_{f}(t(\tau))\left(T_{\text {sat }}-T_{\text {in }}\right)}
\end{gathered}
$$


Setting the transient terms in equations (18) and (19) to zero yields the required initial conditions, if the initial conditions are specified to be a steadystate flow. Since the momentum flux distribution of a fully-developed steadystate flow has an analytical solution

$$
\tau_{r x}(r)=-\frac{d p}{d x} \frac{r_{0}}{2}\left[\left(\frac{r}{r_{0}}\right)-\left\{\frac{1-\left(r_{i} / r_{0}\right)^{2}}{2 \ln \left(r_{0} / r_{i}\right)}\right\}\left(\frac{r_{0}}{r}\right)\right]
$$

the calculation of the initial velocity distribution equation (18) without its transient terms is actually replaced by solving the first order differential equation

$$
\begin{aligned}
& \frac{\partial \dot{U}}{\partial R}=-\left(\sqrt{-\frac{d_{h} L}{\rho_{\rho} \Delta P}}\right) \frac{T_{r x}(r)}{\left(\nu+\epsilon_{M}(r)\right)} \\
& \text { B.C.: } \dot{\varphi}\left(R_{i}\right)=0 \text { or } \dot{l}\left(R_{o}\right)=0 \\
& \text { with } \dot{U}=\frac{u}{\sqrt{-\frac{l_{h}}{4 \rho_{f}} \frac{\partial p}{L}}}
\end{aligned}
$$

where $\dot{I}$ represents a dimensionless velocity, which is established with the initial friction velocity $u_{0}^{*}$. because the initial mean velocity $u_{m 0}$ is not known in this case.

\subsection{Limitations}

Lee and Bankoff [12] used calculations for symmetrical conditions between two flat plates to determine the empirical parameter $C_{S}$. By comparing their result with the hydraulic diameter concept with experimental data $[\bar{\tau}, 21]$, obtained with circular tubes or rectangular channels, whose width and height were of similar magnitude.

The eddy viscosity model proposed by Reichardt [15] is also based on experiments for How in circular tubes. Strictly speaking, the eddy viscosity model in the current form for the annulus does not provide a consistent solution for the velocities $u(r)$ and the momentum flux $\tau_{r r}$. This inconsistency vanishes for ratios of $r_{i} / r_{0}$ converging to one and increases for smaller ratios 
of $r_{i} / r_{0}$. Hence, the model should not be applied to small ratios of $r_{i} / r_{0}$. In general, there should be awareness of the fact that the semi-empirical eddy viscosity model actually was developed for the circular tube, and might not be appropriate for any geometry.

\section{Computational Performance}

The available computational means for the performance of the model was an IBM-PC clone with an INTEL 386DX microprocessor operated by DOS. FORTRAN 77 was chosen as the programming language to enter the code. The calculations were made with a precision of 15 significant digits.

\subsection{Basic Units of the Program}

The computational performance of the described OFI model results in essentially four units:

1. The calculation of the initial steady-state flow conditions with equations (2.1) and (19) with the transient terms set to zero.

2. The flow computation for a discrete forward time with equations (18) and (19).

3. The evaluation of the OSV criterion given by equation (9) after each flow computation.

4. The adjustment of the fluid properties to the new flow conditions after each time step.

\subsection{Numerical Methods}

Equation (24) is integrated with a commercial routine working with the Runge-Kutta algorithm. Since (24) has one more boundary condition than necessary the integration is performed from both walls towards $r_{m}$. Equation 
(19) without its transient terms is solved by the Crank-Nicolson method, together with a commercial tridiagonal matrix solver to obtain the initial temperatures. Since the fluid properties depend on the temperature, which is not known in the beginning, calculating the initial velocity and temperature is actually an iterative process.

The calculation of the velocity for a forward time step also used the Crank-Nicolson method. Equation (11) with its transient terms is. however, a partial differential equation in three dimensions. $A$ difference scheme with a central-difference approximation for the first and second partial derivative with respect to the radius $R$ and a backward-difference approximation for the first derivative with respect to the axial coordinate $X$, which are all taken at the midpoint of the forward time step, according to the Crank-Nicolson approach. is used. This method leads to a number of simultaneous linear equations, which is of the same order as the one for the Crank-Nicolson method, and which again can be solved by the tridiagonal matrix solver. However, using backward-differences results in an error of the first order of the mesh width in the $X$-direction and consequently impairs the convergence. Hence. it has to be reckoned with a considerable error, but the computational means did not leave an alternative.

The integrations of the quantities over the cross section in order to obtain the average are performed with the trapezoidal rule. The fluid properties are calculated with polynomials based upon least-square fits.

A very important prerequisite for performing the above methods successfully is the choice of the right lattice. Since the flow calculation represents a boundary layer problem, a graded net with respect to the distance to the wall is necessary. For the present calculations a stretching method is used, specified by

$$
\begin{aligned}
& \left(r_{j+1}-r_{j}\right)=k_{n}\left(r_{j}-r_{j-1}\right) \text { for } r_{i} \leq r \leq r_{m} \\
& \left(r_{j}-r_{j-1}\right)=k_{n}\left(r_{j+1}-r_{J}\right) \text { for } r_{m} \leq r \leq r_{0}
\end{aligned}
$$

where $k_{n}$ is the stretching parameter. The best convergence of the numerical methods used is found for $k_{n}=1.07$. The whole net size is chosen to $t$ 300 net points for the channel gap and 100 net points for the channel length The dimensionless step size used is $10^{-4}$. The latter values result from $t^{\text {: }}$ convergence test, as well as from the limited memory size operational by DOS and the performance of the computer used. 


\subsection{Error Margins}

For the steady state there are two criteria for which the solution should show consistency. Upon calculating the initial velocity by equation (24), there is one more boundary condition than required. Hence, it is integrated from both walls to the center of the gap. The difference obtained for the velocity at $r_{m}$ was between 2 and 3mentioned in section 2.4 , is dependent on $r_{i} / r_{o}$, which is for the considered conditions about 0.8 , and not due to the numerics. For $r_{i} / r_{o}=0.5$ this error is already larger than $5 \%$. Calculating the steady bulk temperatures must comply with the overall energy balance for the annular flow. For the calculation of the initial conditions the error for the overall energy balance can be kept smaller than $3 \%$ by choosing the right stretching factor. However. for the new final steady state after a pressure drop change, errors of more than $10 \%$ were detected. This error most likely results from the insufficiency of the numerical method applied to solve equation (19), as explained in the previous section. Hence in order to get the bulk velocity a one-dimensional balance is the better choice.

Beside these consistency checks. some results of the flow calculations can be checked by empirical correlations for the steady state. The bulk velocity should comply with the Blasius equation for the friction factor.

$$
\frac{d p}{d x}=-\frac{\lambda}{d_{h}} \frac{\rho_{f}}{2} u_{m n}^{2} \quad \text { with } \quad \lambda=0.316+R e^{-\frac{1}{4}}
$$

Koch and Feind [11] found from their experiments with annuli that the friction factor of the annulus differs by less than $5 \%$ from the one that Blasius found for circular tube. The calculations are in good agreement with this result (Fig. 20). A relatively simple equation to calculate the wall temperature was given by Dittus and Boelter [5]:

$$
N u_{d_{h}}=\frac{h d_{h}}{k_{f}}=0.023 R e^{0.8} P r^{0.4}
$$

The equation can give an error up to $25 \%$. In view of this, the calculation gives very reasonable results (Fig. 7).

The verification of the transient results with such a simple approach is not possible. Hence, the transient will be discussed in depth in section 5.1. 


\section{Steady State Flow Application}

\subsection{Computational Results}

For equal heat fluxes at both walls, the calculations for the conditions of interest essentially yield the same result as the calculations performed by Lee and Bankoff [12] for a channel between two flat plates, which is not surprising for the ratio $r_{i} / r_{0}$ considered of about 0.8 . They presented the results for various conditions of channel height, inlet temperature and saturation temperature. They found that the results for the conditions considered follow approximately

$$
S t=0.076 P e^{-\frac{1}{5}}
$$

where the Stanton and Peclet number are defined as follows

$$
\begin{gathered}
S t=\frac{q}{G c_{p f}\left(T_{\text {sat }}-T_{m}\right)} \\
P \epsilon=\frac{G d_{h} c_{p f}}{k_{f}}
\end{gathered}
$$

Using this equation means a loss of accuracy for the prediction of OFI. However, it saves costly computations and is applicable to the present computer codes for one-dimensional nuclear safety analysis. They also compared their results with experiments of Whittle and Forgan [21] and Dougherty, et al. [7].

It is found that the calculated subcooling for annuli is higher than for flat plates, depending on the radius ratio, $r_{i} / r_{0}$, amounting to about $10 \%$ and $20 \%$, respectively, for $r_{i} / r_{o}=0.5$ and 0.25 . Figure 5 shows a comparison of the results for the Stanton number versus the Peclet number for the parameters given in Table 1 , with varying ratio $r_{i} / r_{0}$. In addition, the calculations also reveal that the outer wall is the wall where the bubble boundary layer first becomes unstable.

If only one wall is heated the subcooling differs from the ones, calculate for two walls heated equally. For the conditions considered the subcoolin. is about 50\% higher. There is no significant difference between heating $t h$ inner or the outer wall. 


\subsection{Experiments performed at Columbia University}

\subsubsection{The Design of the Steady State Experiments}

The experiments were performed with a downward annular water flow. The main part of the experimental arrangement was two Inconel 625 tubes, which were used both to form the flow channel and for electrical resistance heating. The wall thickness for both tubes was about $1.65 \mathrm{~mm}$. A large number of spacer pins was needed to assure the proper annulus gap. Comparing the flow rate versus the pressure drop for all-liquid flow with the model and the Blasius equation (26) shows that the pins increase the flow resistance significantly (Fig. 21). Consequently, the pins actually change the experimental situation in a much more complicated way than that which is modeled. A bypass line was used to vary the flow rate through the test section for different tests, while the bypass line and test section had a constant total flow rate. Fur fixed inlet temperature and heat flux, the flow was varied by an inlet valve in small steps in order to get the pressure drop versus flow rate curve representing one test (Fig. 1). Measurements were made and reported about five minutes after each of those small flow rate changes. The measurements included flow rate, pressure drop, absolute outlet pressure, inlet and mean outlet temperature. as well as wall temperature of the tubes at various locations. The wall temperatures were measured at surfaces not in contact with the fluid. The measurement with the minimum pressure drop was considered as the OFI condition. Operating with stepwise flow rate variations guarantees steady state conditions; however, it also results in a discretization error. In some cases this discretization error for the critical subcooling might be more than $5^{\circ} \mathrm{C}$. The parameters varied included the heat fluxes and the inlet temperature. Some tests were also made with only one wall heated. There is no information about the error range of the various measurements. Table 1 shows the experimental results in detail.

\subsubsection{Comparison with the model}

Comparing the experimental data with the predicted data shows that there is a considerable error for the prediction of the subcooling. Its average value is $3.4^{\circ} \mathrm{C}$ for the test with the same heat flux at both walls. The present model seems to be quite conservative for the conditions considered. 
The quality of the model may be judged by the comparison of the experimental data with two other models, which are the Saha and Zuber correlation [18] and the recent correlation by Rogers, et al. [17].

The Saha and Zuber correlation, which is regarded as an entirely empirical model, unlike the present seni-analytical one, shows almost the same standard deviation, and is also conservative. Which model is actually better has to be decided by experiments with either higher or lower Peclet number's. However, equation (28), as an easy-to-use criterion for OFI, shows no improvement compared to the Saha and Zuber correlation.

The model of Rogers, et al. shows for both contact angles larger standard deviation than the present model, and is also conservative. This semianalytical model differs in the derivation of the drag and surface forces, and the model for the temperature distribution. In order to judge these differences independently, the critical bubble diameter for bubble departure of the present model was applied to the dimensionless temperature profiles given by Martinelli, which Rogers, et al. used. This resulted in very similar values for the critical subcooling as obtained by the model of Rogers, et al. and suggests by itself. that the rigorous two-dimensional temperature calculations with the models of Reichardt and van Driest in the present model constitute the more important difference, and yield better values compared to the approach of Rogers, et al. . Even equation (28) is better than the more complicated model proposed by Rogers, et al. .

The few experiments with only one wall heated show a result which is widely scattered (Fig. 3). Since the parameter of the tests (1) are all of the same order of magnitude. this scatter is assumed to be a result of experimental insufficiencies. While three tests give a subcooling which is of the same size as for two heated walls, one test shows a subcooling even higher than predicted. Hence, it is not possible to judge the validity of the model for an annular flow with only one wall heated by the experimental data.

The complete comparison of the prediction of the critical subcooling for all the models mentioned is shown in Table 2 and Figures 2. 3 and 4. 


\section{Transient Flow Application}

\subsection{Analysis of the Flow Transient}

\subsubsection{Velocity Profiles}

For hydrodynamically fully-developed, steady-state flow, the velocity profile is completely determined by the mean velocity, while for a transient profile it is not. Whether the velocity profile during the flow transient differs appreciably from the steady state profile depends on how fast the shear stress propagates from the wall into the flow, compared to the deceleration of the mean flow. If the shear stress propagation is much slower than the deceleration of the mean flow, there is a significant delay in the response of the boundary layer to the core flow, and neither the steady-state friction factors nor the steady state velocity profiles match those during the transient. The velocities close to the wall. where viscous and static pressure outweigh the inertial forces, are supposed to decrease much faster than the velocities in the core. The ratio between the characteristic times of the flow deceleration and the shear stress propagation is an appropriate parameter to indicate whether there is a significant deviation of the velocity profiles from the steady-state values.

A momentum balance for the bulk fiow, assuming the friction factor to be the steady state value, is

$$
\begin{aligned}
& \frac{\mathrm{d} u_{m}}{\mathrm{~d} t}+\frac{\lambda}{2 d_{h}} u_{m}^{2}=\left.\frac{1}{\varrho} \frac{\mathrm{d} p}{\mathrm{~d} x}\right|_{t} \\
& \text { I.C.: } \quad u_{m}(0)=u_{m, 0}
\end{aligned}
$$

This allows an analytical solution. which reveals the characteristic time

$$
\tau_{u_{m}}=\frac{\varrho d_{h}}{\lambda G_{S S}}
$$

where $G_{S S}$ is the new steady state mass velocity.

The Prandtl solution for the thickness of a turbulent boundary layer on a flat plate

$$
\delta=0.37 \operatorname{Re}_{x}^{-\frac{1}{5}} x
$$


is used to evaluate the shear stress propagation in the transient turbulent flow. The time it takes an observer moving with the flow far away from the plate until the boundary layer reaches a thickness of half of the channel height

$$
\tau_{p, S h}=1.46 \frac{e^{3 / 4}}{\nu^{1 / 4}} \frac{\left(r_{0}-r_{i}\right)^{5 / 4}}{G_{S S}^{3 / 4}}
$$

is taken as the characteristic time for the shear stress propagation.

Thus a rough estimate of the condition for occurrence of deviations from the steady-state velocity profile during the transient is

$$
\frac{\tau_{p, s h}}{\tau_{u_{m}}}=0.61 \lambda \operatorname{Re}_{d_{h}}^{1 / 4} \geq \mathrm{O}(1)
$$

For the present flow-transient experiments with, this is

$$
\frac{\tau_{p, s h}}{\tau_{u_{m}}}=\frac{0.04 \mathrm{~s}}{0.22 \mathrm{~s}}=0.2
$$

Therefore, the transient velocity profiles should differ from the steady state ones, but the deviations are expected to be small.

Dimensionless velocity profiles calculated by a finite-difference method show for the present transient experimental data the same result (Fig. 6).

\subsubsection{Temperature Profiles}

For thermally and hydrodynamically fully-developed steady-state flow, the knowledge of three parameters, which are the mean flow rate, the mean temperature and the wall heat flux, is necessary to determine the temperature profile at the outlet cross-section. Whether the transient outlet temperature profile differs from the steady-state profile with the same parameters depends on how fast the outlet mean temperature rises, compared to the penetration of the changing temperature in the core towards the wall. If the temperature penetration is much slower than the mean temperature rise, there is a delay in the adjustment of the thermal boundary layer to the temperature in the core. and the temperature profile differs from the steady state one. The temperature of the fluid close to the heated wall. where the ronvection and the transient terms are much smaller than the heat conduction, should 
be higher than the temperature in the core. where the convection and the transient terms are of the same order as the heat conduction. As with the velocity profiles, a ratio of characteristic times of both processes is used to obtain an appropriate parameter for evaluating the transient effect on the temperature profiles.

The integration of the energy balance for a bulk flow with its initial and boundary conditions

$$
\begin{aligned}
& \frac{\delta T}{\delta t}+u_{m} \frac{\delta T}{\delta x}=\frac{2 q}{\varrho c_{p}\left(r_{0}-r_{i}\right)} \\
& \text { B.C.: } \quad T(x, t)=T_{0}(x) \\
& \text { I.C.: } \quad T(0, t)=T_{\text {in }}
\end{aligned}
$$

yields a response time for the mean outlet temperature of

$$
\tau_{T_{\text {out }}}=\frac{\varrho L}{G_{S S}}
$$

Analytical solutions for turbulent thermal boundary layers with a given heat flux are very restricted. For the special case with the laminar and turbulent Prandtl numbers close to one the turbulent thermal boundary layer thickness on a flat plate with constant temperature is about the same as the hydrodynanuc boundary layer. Owing to this fact, the characteristic time for the temperature penetration is roughly estimated to be of similar size as the characteristic time for the shear stress propagation.

$$
\tau_{p . T} \sim \tau_{p, s h}
$$

For times of the same order as the mean outlet temperature response time, the condition for the temperature profile at the outlet to be significantly different from that at steady state is given by

$$
\frac{\tau_{p, s h}}{\tau_{T_{\text {out }}}}=0.61 \frac{d_{\mathrm{h}}}{L} \operatorname{Re}_{d_{\mathrm{h}}}^{1 / 4} \geq \mathrm{O}(1)
$$

and yields for the transient flow experiments

$$
\frac{\tau_{p, \text { sh }}}{\tau_{T_{\text {out }}}}=\frac{0.04 \mathrm{~s}}{1.03 \mathrm{~s}}=0.04
$$


Consequently, the temperature profiles during the transient in the time range of interest are not expected to differ significantly from the steady state ones.

The numerical solution for our flow model confirms this result for the parameters of the present experiments (Fig. 7).

\subsection{OFI Prediction During the Transient}

It is thought that the possible differences in the prediction of OFI during a transient should be caused mainly by different local velocities and temperatures close to the wall. Assuming differences which are significant for the prediction of OFI, the force balance for a bubble at the wall yields a stabilizing effect due to the lower local velocities close to the wall and a destabilizing effect due to the higher local temperatures. That means the critical diameter for the bubble departure increases. as well as the distance between the wall and the location where the fluid has saturation temperature. Numerical solutions and experiments are necessary to show which effect actually predominates, or if they are significant at all.

Since the force balance is not based on local velocities, the computational results might only show the destabilizing effect. For the experimental data that is not a serious limitation, because of OFI in a time range which is larger than the bulk velocity response time, but might be of interest for a system which operates in the steady-state much closer to the OFI conditions. Actually, numerical calculations do not show any significant difference in the subcooling between the steady state and the transient flow with the same heat flux and mass velocity even for OFI, which occurs for highly transient conditions (Fig. 8).

\subsection{Experiments performed at Columbia University}

\subsubsection{Design of the Transient Experiments}

For the transient experiments the same equipment was used as for the steady state experiments. The step change in the pressure drop across the tes, section was realized by diverting a portion of the flow through a bypass 
line of a similar flow resistance as the heated test section, using a quickacting valve, while the flow rate through the pump stays constant. The smallest available bypass line for given heat fluxes and inlet temperatures was chosen for the transient experiments which did not show OFI for steady state conditions. If high temperatures were detected, the power was immediately cut off to terminate the transient. The high temperatures are interpreted as the occurrence of OFI. Parameters of the various runs are shown in Table 3. The profiles for flow rate, pressure drop, heat flux, mean outlet temperature, saturation temperature and outlet wall temperatures, at the outlet are shown for one run with and one run without automatic termination in Figures 9 to 16. The flow rate was measured by turbine flow meters, which are supposed to be sensitive to inertial effects. As for the steady state experiments, the wall temperatures shown represent the temperatures at those wall surfaces which are not in contact with the liquid. The reason for the noisy signal for the pressure drop is not known.

\subsubsection{Comparison With the Model}

The experiments differ crucially in one respect from the actual situation in the loss-of-coolant analysis and also the constant pressure drop assumption. The system of test section and bypass line has a constant imposed flow rate rather than a pressure boundary condition. The bypass is too small to maintain a constant pressure drop once the flow resistance increases due to bubble formation (Figs. 9 and 10). Since the instability phenomenon considered is the flow excursion or Ledinegg instability, whose instability criterion is

$$
\left.\frac{\partial \Delta p}{\partial G}\right|_{\text {demand }}>\left.\frac{\partial \Delta p}{\partial G}\right|_{\text {supply }}
$$

the change from

$$
\left.\frac{\partial \Delta p}{\partial G}\right|_{\text {supply }}=0
$$

for the constant pressure drop boundary condition in the reactor problem to

$$
\left.\frac{\partial \Delta p}{\partial G}\right|_{\text {supply }}<0
$$


in the experiment with insufficient bypass can result in important differences. Hence, the experimental pressure drop profiles for the test with OFI show significantly higher pressure drop and a lower flow rate, and only after a longer time is followed by OF( (Figs. 9 and 10). Therefore, the desired OFI condition for the pressure boundary condition may not be exactly the same as the measured one. In particular, the actual boundary conditions in the experiment will delay OFI and show a lower subcooling at OFI, as may be concluded from the steady-state rapid variation in the experimental subcooling in the vicinity of the pressure drop minimum (Figs. 1 and 18).

Since the heat capacity of the heated walls is of similar size to that of the liquid contents in the annulus, the reported heat flux, which was the heat generation in the wall per unit area $\Gamma$. is expected to be higher than the real heat flux $q$ into the fluid. By assuning the temperature in the wall to be constant in the radial direction and the inner and the outer wall temperatures to be equal. the heat flux can be calculated by the following energy balance:

$$
\begin{aligned}
& \delta_{1} c_{p w} \rho_{w} \frac{\partial T_{w}}{\partial t}=\Gamma_{H}-q(x, t) \\
& \frac{d_{h}}{t} \rho_{f} c_{p f}\left[\frac{\partial T_{m}}{\partial t}+u_{m}(t) \frac{\partial T_{m}}{\partial x}\right]=q(x, t) \\
& \text { B.('.: } T_{m}(0, t)=T_{m i l} ; \quad h\left[T_{w}(x, t)-T_{n}(x, t)\right]=q(x, t) \\
& \text { I.C'.: } T_{m}(x, 0)=T_{m u}(x) ; \quad \Gamma_{w}(x, 0)=T_{w 0}(x)
\end{aligned}
$$

Figure 19 shows a numerical solution for the conditions given in test (' with the heat transfer coefficient calculated with the Dittus-Boelter equation (27) and the bulk velocity obtained by the analytical solution of equation (31). According to this approximation. at OFI the difference between the actual flux and the reported heat generation is for all tests less than $5 \%$. Hence. this error is not considered further.

Plotting the Stanton number over the Peclet number for the reported OFI conditions first of all reveals, that the experimental OFI results again are widely scattered (Fig.17). Since all runs have almost the same parameters. the scatter should indicate non-reproducible conditions of the experiments. Comparing Figure 17 with the corresponding one for the steady-state dat. which is Figure 2 shows that there is at present no evidence to reject the hypothesis that there is no transient effect. 
Aside the problems with the experimental design, there were at that time only three runs, with almost the same parameters. Thus, it would not be appropriate to draw final conclusions whether there are transient effects.

\section{Conclusions}

1. No evidence was discovered that a flow transient affects OFI prediction with steady-state correlations for the conditions of interest. The criterion for this is equations (35) and (39).

2. There is no evidence that a ratio $r_{o} / r_{i}$ of 0.8 significantly affects the prediction of OFI for annuli with methods appropriate for flat channels. This should not be applied to very small diameter ratio.

3. The subcooling at OFI for the conditions considered is $50 \%$ higher if only one wall is heated. There is no significant difference between heating the inner or the outer wall.

4. The correlation presented is conservative and shows considerably smaller deviations compared to other correlations for the steady-state experiments considered, when the both walls are equally heated.

5. In order to extend the validity of the correlation the flow calculation should be improved by considering the variation of the fluid properties in the flow direction.

6. Improved experimental design and many more data points are needed in order to validate the theoretical results for the OFI prediction in transient flow, as well as for the prediction of OFI in annuli with only one wall heated. 


\title{
Notation
}

\author{
$\mathrm{A}^{+}$damping constant \\ $C$ coefficient \\ $C_{p}$ specific heat $\left[\mathrm{J} / \mathrm{kg}^{\circ} \mathrm{C}\right]$ \\ $d_{h}$ hydraulic diameter $[\mathrm{m}]$ \\ $F$ force $[\mathrm{N}]$ \\ $G$ mass velocity $\left[\mathrm{kg} / \mathrm{m}^{2} \mathrm{~s}\right]$ \\ $g \quad$ acceleration due to gravity $\left[\mathrm{m} / \mathrm{s}^{2}\right]$ \\ $h$ heat transfer coefficient $\left[\mathrm{W} / \mathrm{m}^{2}{ }^{\circ} \mathrm{C}\right]$ \\ $K$ parameter used in equation (4) \\ $K_{1}$ parameter used in equation (7) \\ $K_{2}$ parameter used in equation (7) \\ $k \quad$ thermal conductivity $(\mathrm{W} / \mathrm{m} \mathrm{K}$ ) \\ $L$ channel length $[\mathrm{m}]$ \\ $P$ dimensionless pressure \\ $p$ pressure $[\mathrm{Pa}]$ \\ $q$ heat flux $\left[\mathrm{W} / \mathrm{m}^{2}\right]$ \\ $R$ dimensionless radial coordinate \\ $R_{b}$ bubble radius [m] \\ $r$ radial coordinate $[\mathrm{m} / \mathrm{s}]$ \\ $T$ liquid temperature $\left[{ }^{\circ} \mathrm{C}\right]$ \\ $T_{W}$ wall surface temperature $\left.{ }^{\circ} \mathrm{C}\right]$ \\ $t$ time [s] \\ $\zeta$ dimensionless velocity in $x$ direction \\ $\dot{i}$ dimensionless velocity in $x$ direction \\ $u$ velocity in $x$ direction $[\mathrm{m} / \mathrm{s}$ ] \\ $u^{*} \quad$ friction velocity $[\mathrm{m} / \mathrm{s}]$ \\ .' dimensionless axial coordinate \\ $x$ axial coordinate $[\mathrm{m} / \mathrm{s}]$
}




\section{Greek Symbols}

$\begin{array}{ll}\alpha & \text { thermal diffusivity }\left[\mathrm{m}^{2} / \mathrm{s}\right] \\ \delta & \text { hydrodynamic boundary layer thickness }[\mathrm{m}] \\ \Delta T_{\text {sub }} & \text { subcooling }\left[{ }^{\circ} \mathrm{C}\right] \\ \Delta t_{O F I} & \text { time betiveen pressure drop change and OFI }[\mathrm{s}] \\ \epsilon_{H} & \text { eddy thermal diffusivity }\left[\mathrm{m}^{2} / \mathrm{s}\right] \\ \epsilon_{M} & \text { eddy viscosity }\left[\mathrm{m}^{2} / \mathrm{s}\right] \\ \Gamma_{H} & \text { heat generation per area wall surface }\left[\mathrm{W} / \mathrm{m}^{2}\right] \\ \lambda & \text { Darcy friction coefficient } \\ \theta & \text { dimensionless temperature } \\ \nu & \text { kinematic viscosity }\left[\mathrm{m}^{2} / \mathrm{s}\right] \\ \rho & \text { density }\left[\mathrm{kg} / \mathrm{m}^{3}\right] \\ \sigma & \text { surface tension }[\mathrm{N} / \mathrm{m}] \\ \tau & \text { dimensionless time coordinate } \\ & \text { characteristic time }[\mathrm{s}] \\ \tau_{r x} & \text { shear stress }\left[\mathrm{N} / \mathrm{m}^{2}\right] \\ l & \text { parameter used in Fig. } \mathrm{S}\end{array}$

\section{Dimensionless Groups}
$\mathrm{Nu}$ Nusselt number
$P e$ Peclet number
$\operatorname{Pr}$ Prandtl number
$\mathrm{Pr}_{t}$ turbulent Prandtl number
Re Reynolds number
$S t$ Stanton number 


\section{Subscript}

$\begin{array}{ll}B & \text { buoyancy } \\ b & \text { bubble } \\ D & \text { drag } \\ f & \text { liquid } \\ g & \text { gas } \\ i & \text { inner wall } \\ \text { in } & \text { inlet } \\ j & \text { j-th net point in r-direction } \\ m & \text { bulk flow } \\ & \text { axial cross-section average } \\ o & \text { outer wall } \\ \text { out } & \text { outlet } \\ p & \text { propagation } \\ S & \text { surface tension force } \\ S S & \text { steady-state } \\ \text { sat } & \text { saturation } \\ \text { sh } & \text { shear stress } \\ w & \text { wall } \\ 0 & \text { initial state }\end{array}$

\section{Superscript}

+ dimensionless

\section{References}

[1] R. M. Al-Hayes and R. H. S. Winterton, bubble diameter on detachment in flowing liquids. Int. J. Heat .Mass Transfer $24,223-230$ (1981)

[2] A. A. Avdeev, Application of the Reynolds analogy to the investigation of surface boiling in conditions of forced motion, High Temperature 24. 100-108 (1986) 
[3] S. (i. Bankoff, S. C. Lee and A. Knaani, Literature review of forcedconvection subcooled nucleate boiling, Report No. SGB-91.01, Westing. house Savannah River C'ompany (1991)

(4) J. G. Collier, Convective Boiling and Condensation, second edition, chapter 6, 178-205, Mc-Graw Hill, New York (1981)

(5) F.W. Dittus and L. M. K. Boelter, Univ. Calif., Berkely, Publ. Eng. 2, $433(1930)$

(0) H. Dorra, S. C'. Lee and S. G. Bankoff, Onset of significant void in forced convection subcooled boiling, unpublished report (1991)

(7) T. Dougherty, C. Fighetti, G. Reddt, B. Yang, T. Jafri, E. McAssey and Z. Qureshi. Flow boiling in vertical down-flow, Proceedings of $10 \mathrm{th}$ Int. Heat Transfer Conf. 6 . 9-14 (1990)

(\$) E. R. van Driest, On turbulent How near a wall, Paper No. 12, Heat Transfer and Fluid Mechanics Institute Symposium, University of California. Los Angeles. CA (195j)

(9. B. Sohnston. Subcooled boiling of downward flow in a vertical annulus, Report No. DPST-88-891. Savannah River Laboratory, Aiken. SC (1988)

[10] H. Kawamura, Experimental and analytical study of transient heat transfer for turbulent flow in a circular tube. Int. J. Heat Mass Transfer $20.443-450(1977)$

[4] R. Koch and K. Feind, Druckverlust und Wärmeübergang in Ringspalten. Chemie-Ing. Techn. 30, 577-584 (1958)

[12] S. C. Lee and S. G. Bankoff, Stability of Forced-Convection Subcooled Boiling, unpublished report (1991)

[A3] S. Levy, Forced convection subcooled boiling: prediction of vapor volumetric fraction, Int. J. Heat Mass Transfer 10,951-965 (1967)

(14) R. C. . Martinelli, Heat transfer to molten metals, Trans. ASME 6 .941$947(1947)$ 
[15] H. Reichardt. Vollständige Darstellung der turbulenten Geschwindigkeitsverteilung in glatten Leitungen, Z. Angew. Math. Mech. 31, 208-219 (1951)

[16] J. T. Rogers, M. Salcudean, Z. Abdullah, D. McLeod and D. Poirier, The onset of significant void in up-flow boiling of water at low pressure and velocities.Int. J. Heat Mass Transfer 30 2247-2260 (1987)

[17] J. T. Rogers and Jing-Hui Li, Prediction of the onset of significant void in flow boiling water, Dept. of Mechanical and Aerospace Engineering, Carleton University, Ottawa, report (1992)

[18] P. Saha and ... Zuber, Point of net vapor generation and vapor void fraction in subcooled boiling, Proceedings of Fifth International Heat Transfer Conference, 4, 175-179 (1974)

[19] F. W. Staub. The void fraction in subcooled boiling: prediction of the initial point of net vapor generation. J. Heat Transfer 90, 151-157 (1968)

[20] F. M. White. Heat and mass transfer, Chapter 6, 315-332, AddisonIVesley Publishing Co., Reading, Massachusetts (1988)

[21] R. H. Whittle and R. Forgan, Correlation for the minima in the pressure drop versus flow-rate curves for subcooled water flowing in narrow heated channels. Nuclear Engineering and Design 6 . 89-99 (1967)

[22] N. W. Wilson and J. O. Medwell, An analysis of the developing turbulent hydrodynamic and thermal boundary layers in an internally heated annulus, J. Heat Transfer 93 , 25-32 (1971)

[23] R. H. S. Winterton, bubble diameter on detachment in flowing liquids, Int. J. Heat . Yass Transfer $24,223 \cdot 230$ (1984) 


\section{Tables}

\begin{tabular}{|c|c|c|c|c|c|c|}
\hline test & $\begin{array}{c}\text { pressure } \\
\text { at } \\
\text { outlet } \\
\text { [bar] }\end{array}$ & mass velocity & $\begin{array}{c}\text { heat flux } \\
\text { at inner } \\
\text { wall } \\
{\left[\frac{\mathrm{MW}}{\mathrm{m}^{2}}\right]}\end{array}$ & $\begin{array}{c}\text { heat flux } \\
\text { at outer } \\
\text { wall } \\
{\left[\frac{\mathrm{MW}}{\mathrm{m}^{2}}\right]}\end{array}$ & $\begin{array}{c}\text { fluid inlet } \\
\text { temper- } \\
\text { ature } \\
{\left[{ }^{\circ} \mathrm{C}\right]}\end{array}$ & $\begin{array}{l}\text { sub- } \\
\text { cooling } \\
{\left[{ }^{\circ} \mathrm{C}\right]}\end{array}$ \\
\hline 1 & 4.5 & 1,260 & 0.63 & 0.62 & 25 & 14 \\
\hline 2 & 4.5 & 1,260 & 0.62 & 0.63 & 25 & 17 \\
\hline 3 & 3.1 & 1,490 & 0.63 & 0.63 & 31 & 10 \\
\hline 4 & 4.5 & 2,730 & 1.26 & 1.25 & 25 & 20 \\
\hline 5 & 2.4 & 3.140 & 1.26 & 1.26 & 25 & 10 \\
\hline 6 & 4.5 & 3,230 & 1.26 & 1.26 & 50 & 12 \\
\hline$i$ & 4.4 & 3,240 & 1.26 & $1.2 \hat{\imath}$ & 50 & 12 \\
\hline$s$ & 2.2 & 4,360 & 1.25 & 1.26 & 50 & 9 \\
\hline 9 & 4.7 & 6,160 & 2.52 & 2.53 & 49 & 11 \\
\hline 10 & 4.5 & 1,410 & 1.40 & - & 25 & 25 \\
\hline 11 & 4.6 & 2,970 & 2.79 & - & 24 & 29 \\
\hline 12 & 10.4 & 1,300 & - & 1.14 & 24 & 54 \\
\hline 13 & 4.4 & 2,860 & - & 2.30 & 26 & 23 \\
\hline
\end{tabular}

Geometry of the annulus: inner diameter $29.1 \mathrm{~mm}$. outer diameter $36.8 \mathrm{~mm}$. heated length $3.62 \mathrm{~m}$; fluid: water; the minimum of pressure drop versus flow rate demand curve is used for determination of OFI condition; the error margin for the subcooling reported is approximately $\pm 3^{\circ} \mathrm{C}$ for tests 1 through 9.

Table 1: Single annulus steady state flow excursion data taken at the Columbia University Heat Transfer Research Facility in 1990 


\begin{tabular}{|c|c|c|c|c|c|}
\hline test & $\begin{array}{c}\text { measure- } \\
\text { ment } \\
(0 \mathrm{C})\end{array}$ & $\begin{array}{c}\text { present } \\
\text { correlation } \\
\left({ }^{\circ} \mathrm{C}\right]\end{array}$ & $\begin{array}{c}\text { equation } \\
(28)\end{array}$ & $\begin{array}{c}\text { Saha and } \\
\text { Zuber }[18]\end{array}$ & $\begin{array}{c}\text { Rogers } \\
\text { et al. [17] } \\
\theta_{0}=30^{\circ} \\
(0 \mathrm{C}]\end{array}$ \\
\hline 1 & 14 & 16 & 16 & 18 & 15 \\
2 & 17 & 16 & 16 & 18 & 15 \\
3 & 10 & 13 & 15 & 16 & 14 \\
4 & 20 & 18 & 18 & 17 & 19 \\
5 & 10 & 15 & 16 & 15 & 17 \\
6 & 12 & 15 & 16 & 15 & 17 \\
7 & 12 & 15 & 16 & 14 & 17 \\
8 & 9 & 12 & 12 & 11 & 13 \\
9 & 11 & 17 & 19 & 15 & 20 \\
10 & 25 & 45 & 34 & 36 & 31 \\
11 & 29 & 49 & 37 & 34 & 39 \\
12 & 54 & 49 & 29 & 32 & 26 \\
13 & 23 & 41 & 32 & 30 & 33 \\
\hline & & 3.4 & 4.1 & 3.6 & 4.9 \\
\hline
\end{tabular}

Standard deviation for tests 1 through 9:

$$
\sigma_{a}=\sqrt{\frac{1}{9} \sum_{i=1}^{9}\left[\Delta T_{O S V}(\text { measured })_{i}-\Delta T_{O S V}(\text { predicted })_{i}\right]^{2}}
$$

Table 2: Comparison of the subcooling at OSV of the present experimental steady state data with predictions by various correlations 


\begin{tabular}{|c|c|c|c|c|c|c|c|c|}
\hline test & $\begin{array}{c}\text { press- } \\
\text { ure } \\
\text { at } \\
\text { outlet } \\
\text { [bar }]\end{array}$ & $\begin{array}{c}\text { wall } \\
\text { heat } \\
\text { gener- } \\
\text { ation } \\
{\left[\frac{\mathrm{MW}}{\mathrm{m}^{2}}\right]}\end{array}$ & $\begin{array}{c}\text { fluid } \\
\text { inlet } \\
\text { temper- } \\
\text { ature } \\
{\left[{ }^{\circ} \mathrm{C}\right]}\end{array}$ & $\begin{array}{c}\text { final } \\
\text { mass } \\
\text { velocity } \\
{\left[\frac{\mathrm{kg}}{\mathrm{m}^{2} \mathrm{~s}}\right]}\end{array}$ & $\begin{array}{c}\text { initial } \\
\text { mass } \\
\text { velocity } \\
{\left[\frac{\mathrm{kg}}{\mathrm{m}^{2} \mathrm{~s}}\right]}\end{array}$ & $\begin{array}{c}\text { time } \\
\text { of } \\
\text { OFI } \\
{[\mathrm{s}]}\end{array}$ & $\begin{array}{c}\text { mass } \\
\text { velo- } \\
\text { city } \\
{\left[\frac{\mathrm{kg}}{\mathrm{m}^{2} \mathrm{~s}}\right]}\end{array}$ & $\begin{array}{c}\text { sub- } \\
\text { cool- } \\
\text { ing } \\
{\left[{ }^{\circ} \mathrm{C}\right]}\end{array}$ \\
\hline $\mathrm{A}$ & 4.5 & 1.90 & 25 & 9.000 & 4,190 & - & - & - \\
$\mathrm{B}$ & 4.5 & 1.90 & 25 & 9.040 & 4,120 & - & - & - \\
$\mathrm{C}$ & 4.9 & 1.90 & 25 & 9,040 & 3.630 & 2.45 & 3,320 & 27 \\
$\mathrm{D}$ & 5.7 & 1.89 & 25 & 9.000 & 3,720 & 4.34 & 3,140 & 18 \\
$\mathrm{~F}$ & 6.1 & 1.90 & 25 & 9,020 & 3,700 & 3.77 & 2,860 & 21 \\
$\mathrm{G}$ & 4.6 & 1.89 & 25 & 9.020 & 4,120 & - & - & - \\
\hline
\end{tabular}

Geometry of the annulus: inner diameter $29.1 \mathrm{~mm}$, outer diameter $36.8 \mathrm{~mm}$. heated length $3.62 \mathrm{~m}$; fluid: water; wall heat generation is given per flow channel surface area; the flow transient is realized by a sudden opening of a bypass of a similar size as the test section; the heater is turned off either automatically in case of a sudden increase of the wall temperatures or manually after about five seconds; the sudden increase of wall and fluid temperatures is used for the determination of OFI;

Table 3: Single annulus transient flow excursion data taken at the Columbia University Heat Transfer Research Facility in 1990 


\section{Figures}

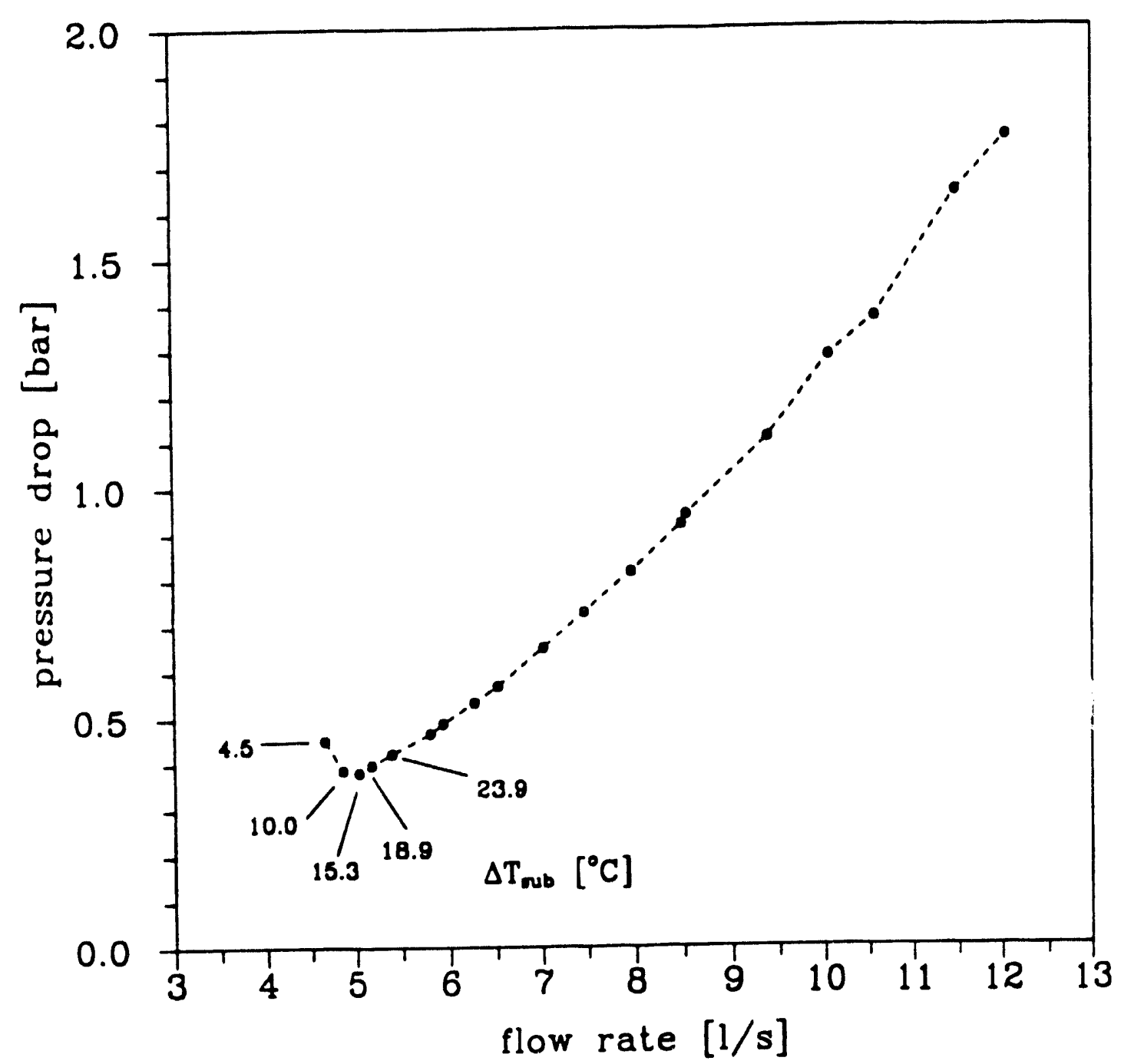

Figure 1: Pressure drop, subcooling and flow rate - experimental result of test 1 


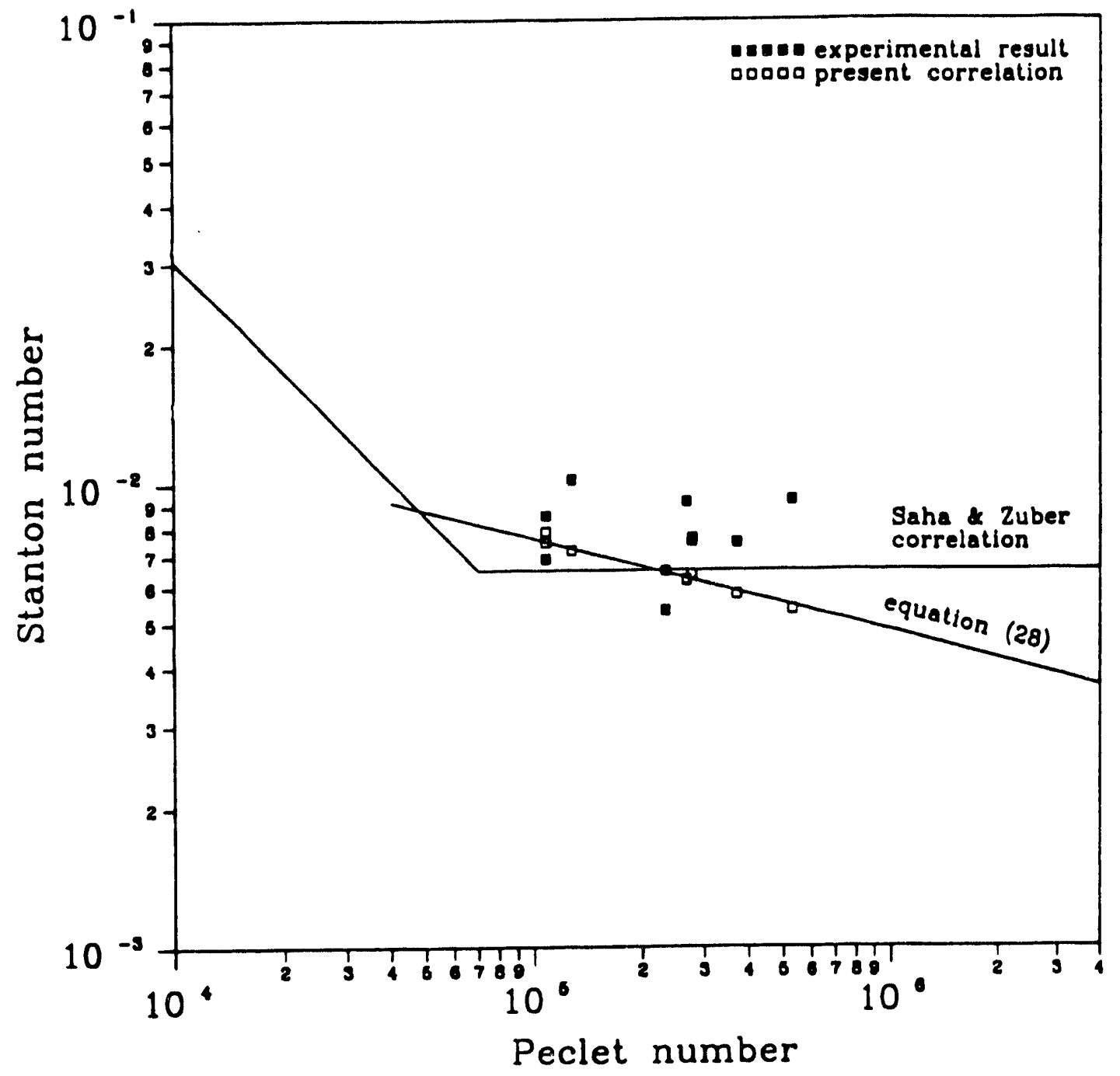

Figure 2: Stanton number versus Peclet number at OFI - tests 1 through 9 


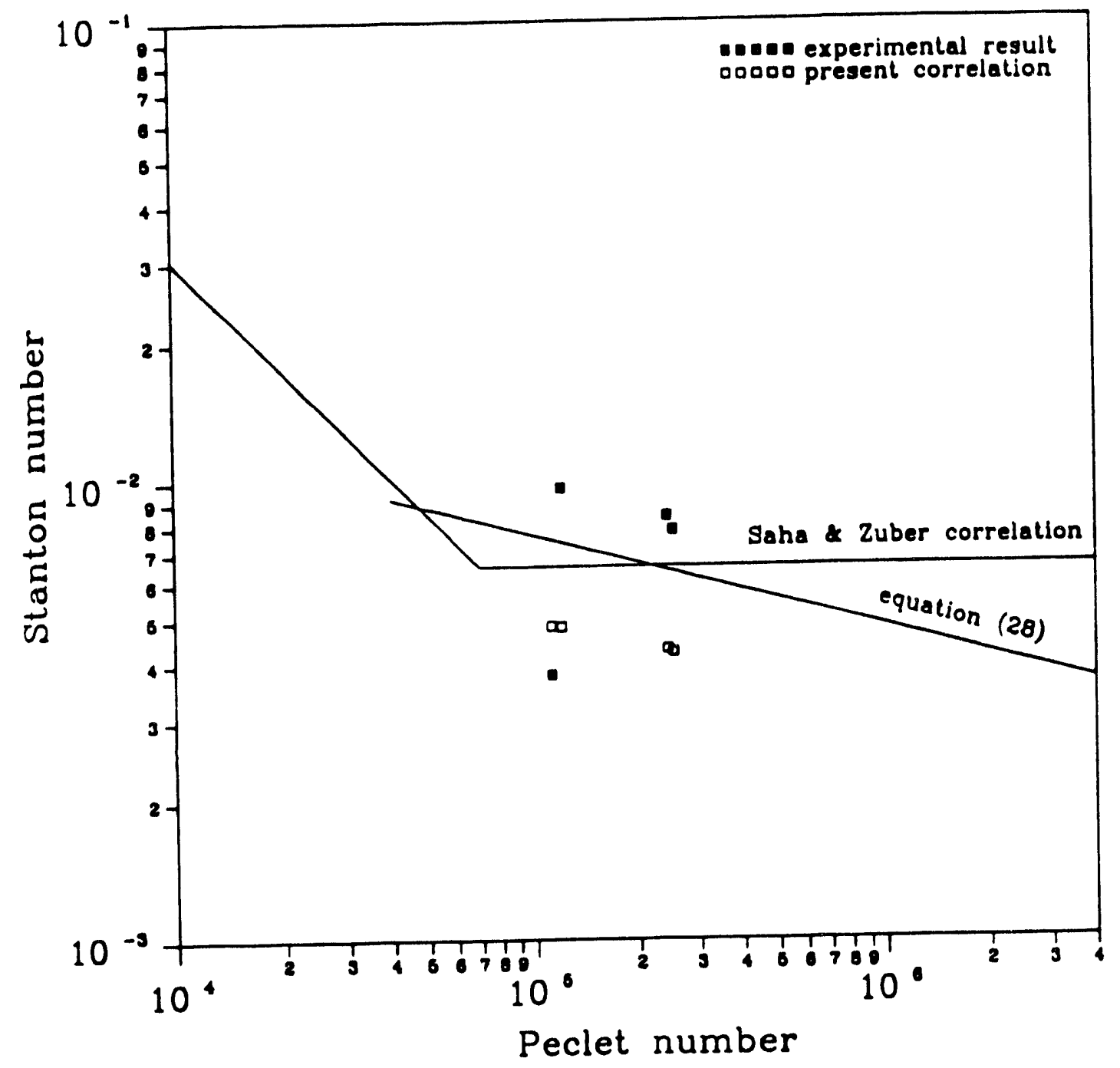

Figure 3: Stanton number versus Peclet number at OFI - tests 10 through 13 


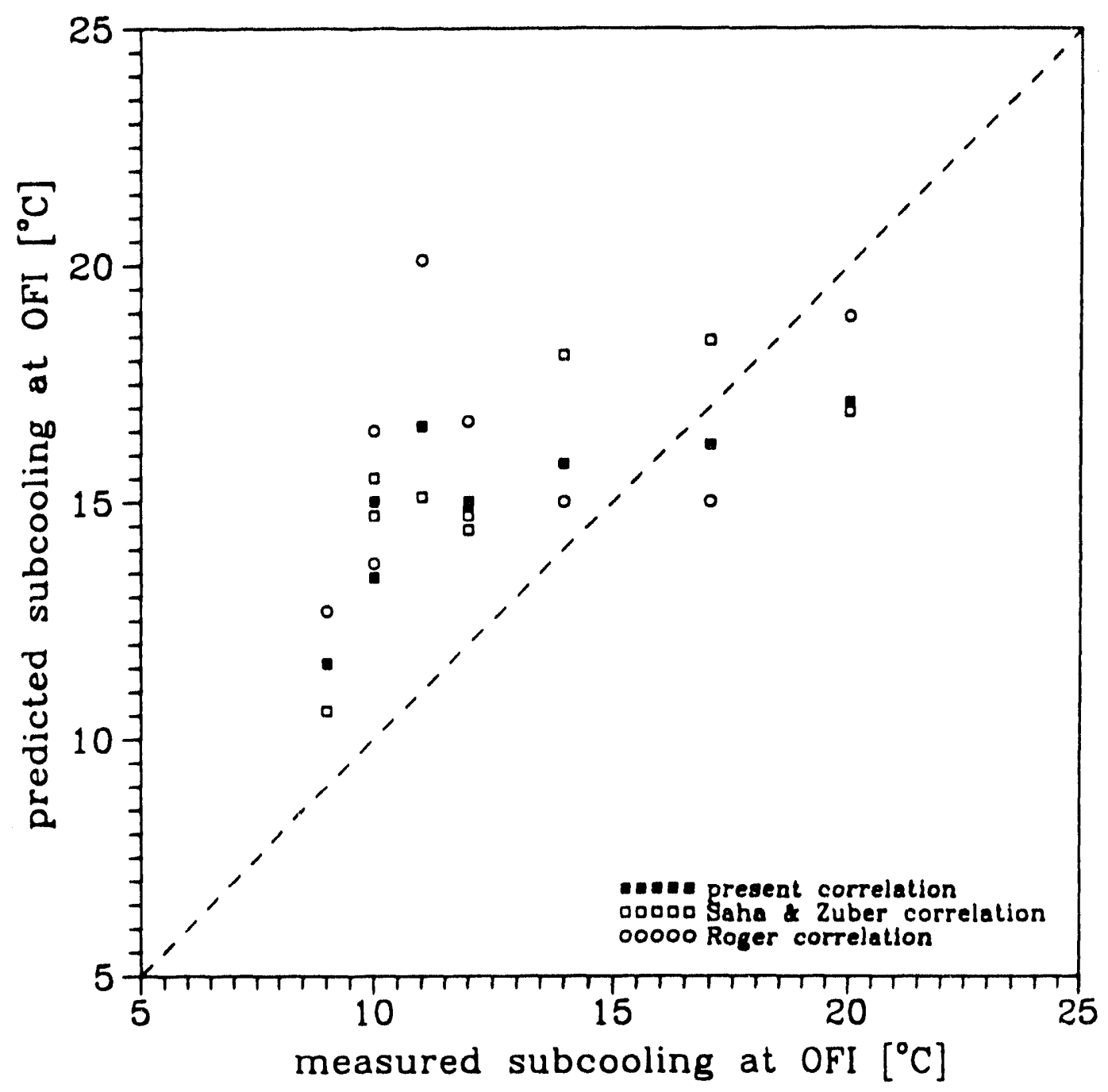

Figure 4: Subcooling at OFI - tests 1 through 9 


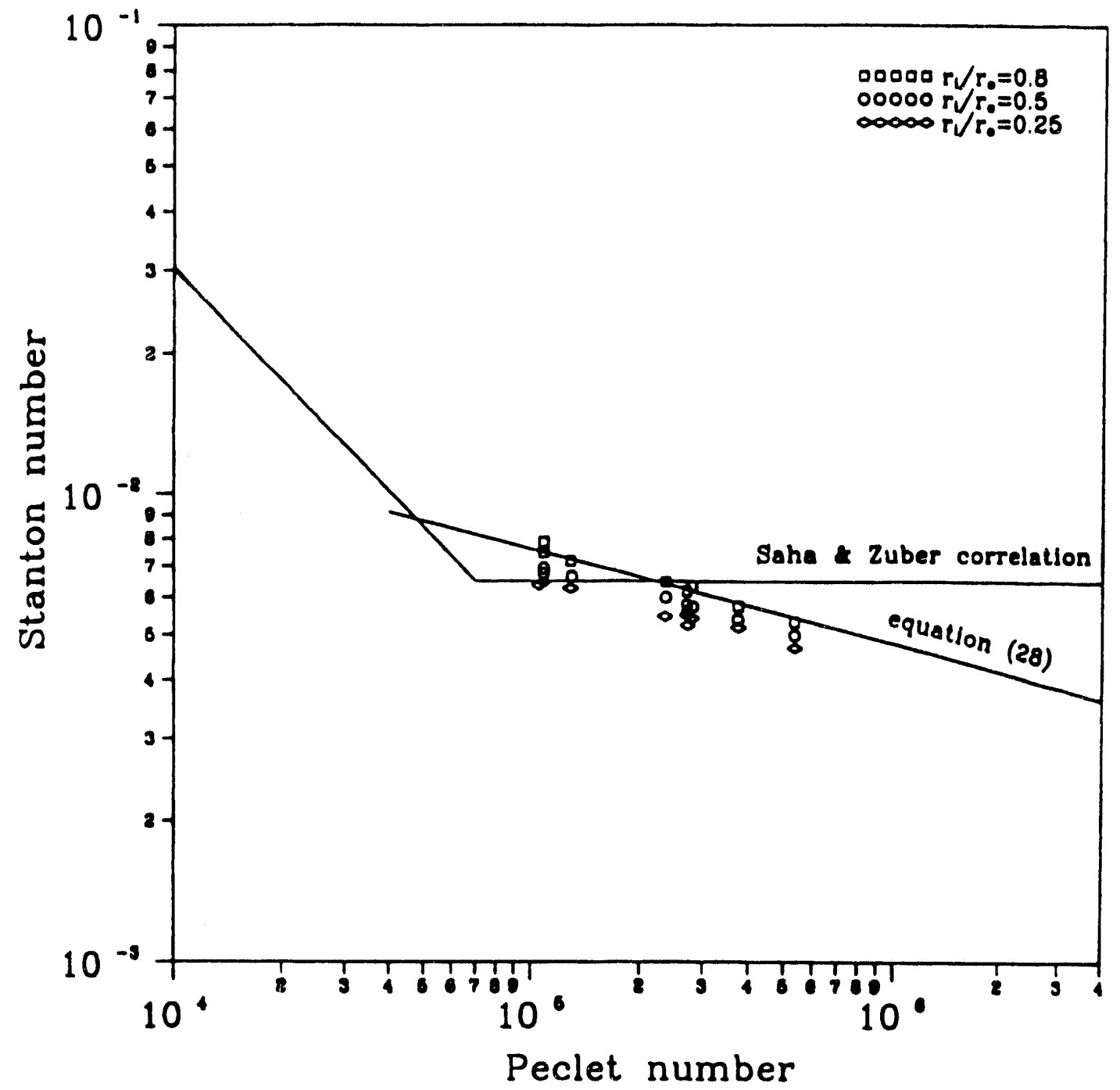

Figure 5: Stanton number versus Peclet number - computational result for various diameter ratios $r_{i} / r_{0}$ 


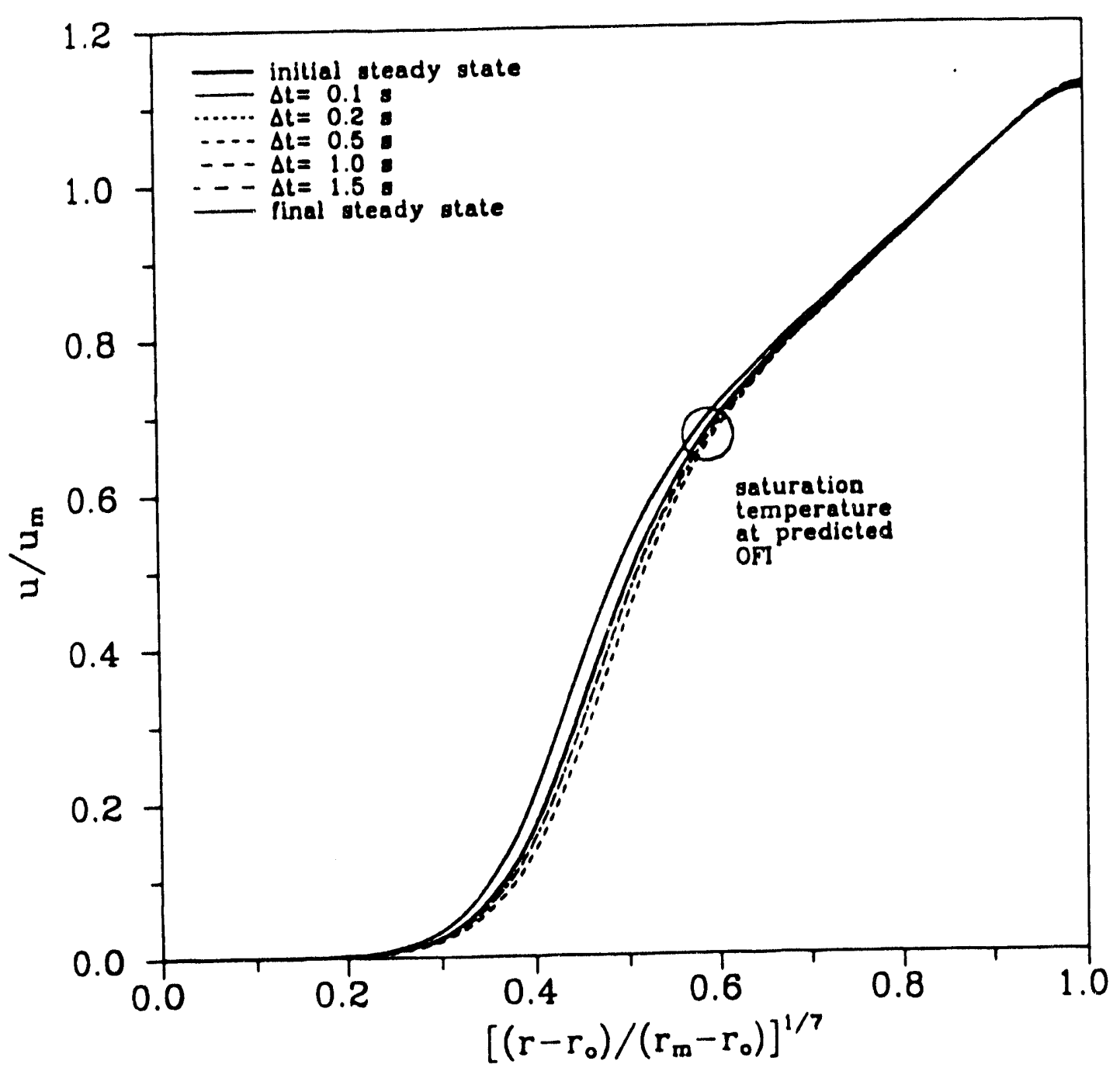

Figure 6: Transient velocity profiles - computational result for test $\mathrm{C}$ 


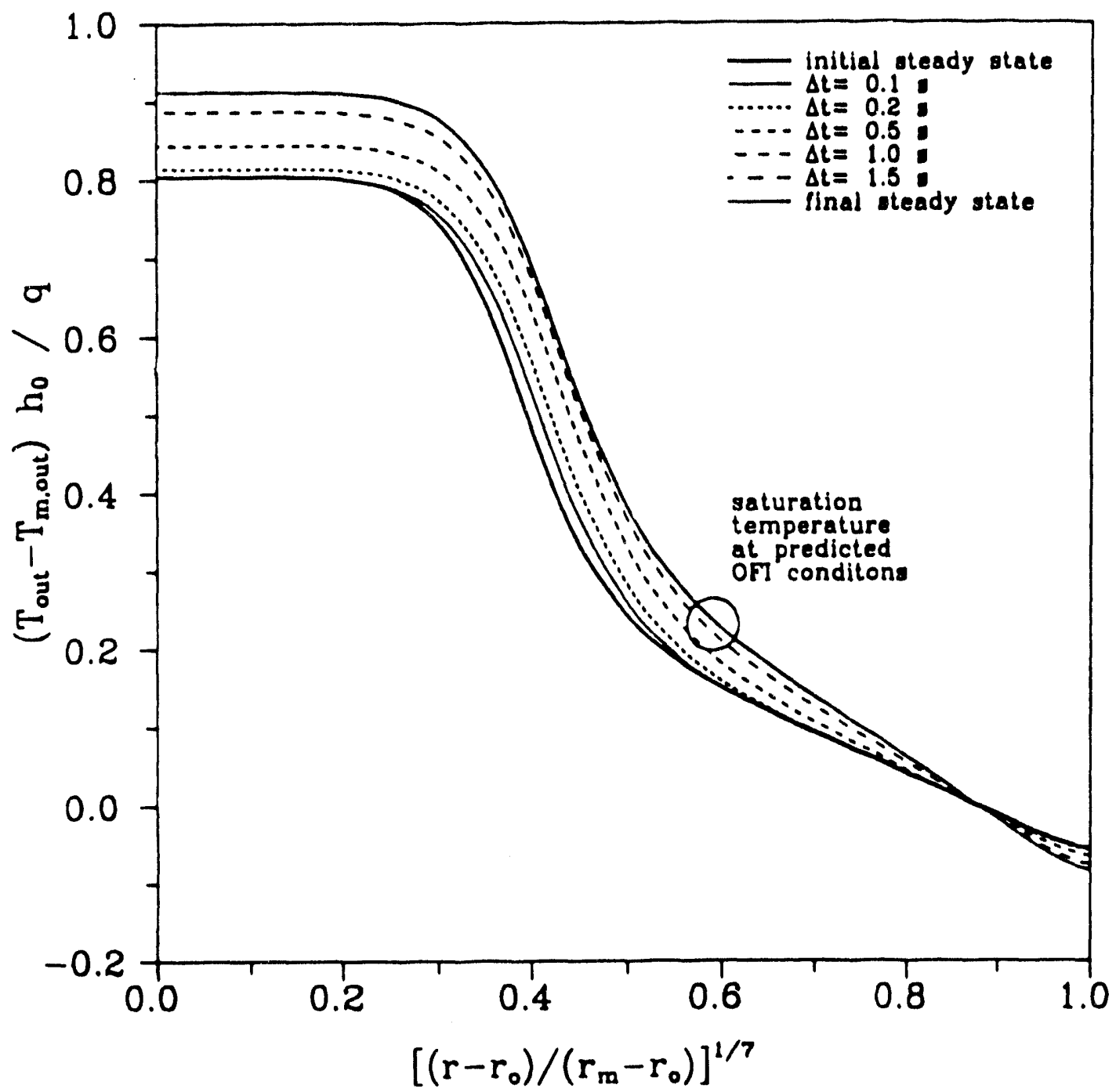

Figure 7: Transient temperature profiles - computational result for test C 


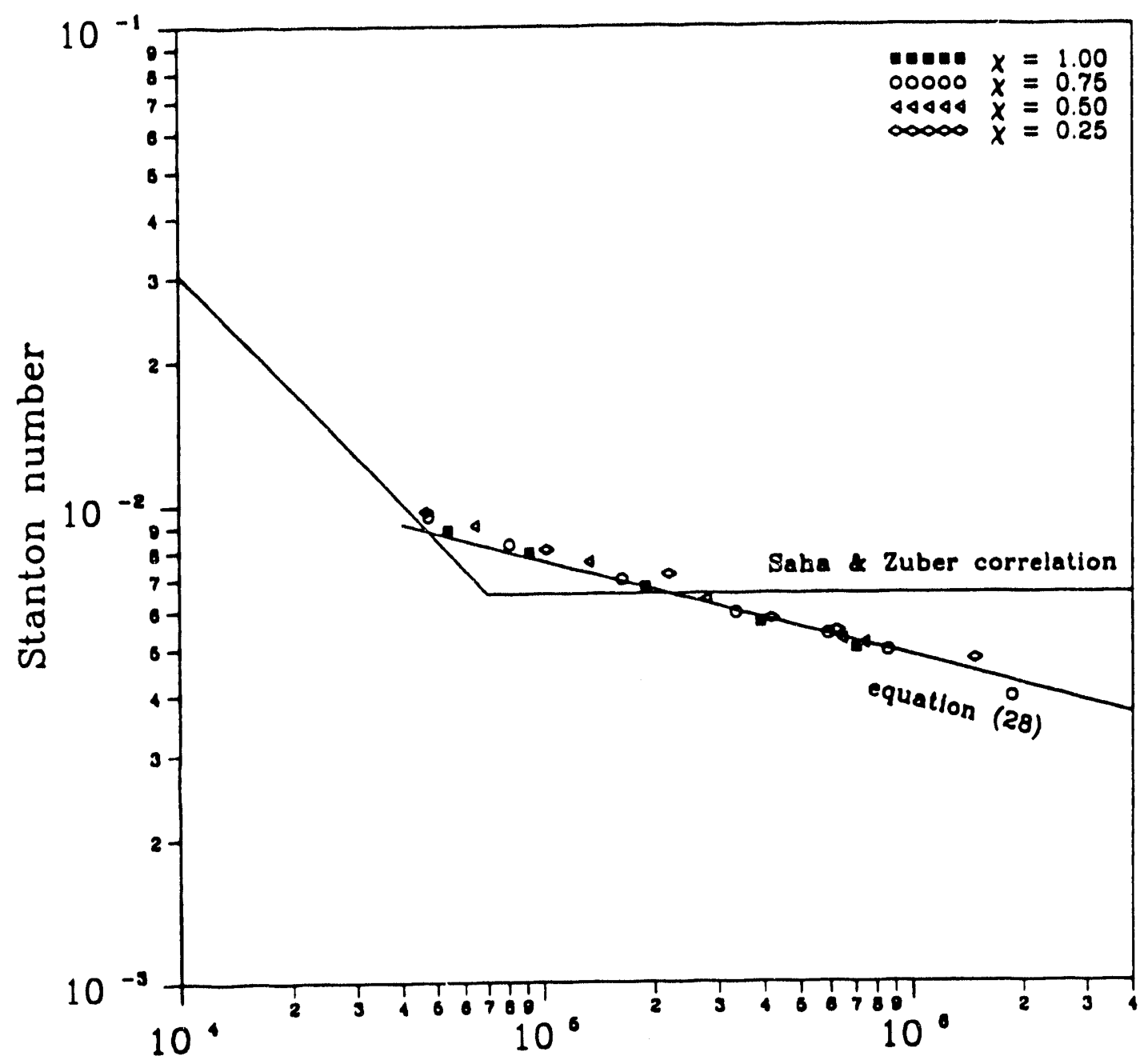

Peclet number

The results shown were calculated for the geometry, the inlet and saturation temperatures of the experiment and a broad range of possible parameters for the mass velocity and its corresponding heat fluxes. Different transient states are distinguished by $\chi=\left(T_{\text {out }, O F I}-\right.$ $\left.T_{\text {ous }, 0}\right) /\left(T_{\text {our, }}-T_{\text {out }, 0}\right)$ where $T_{\text {out, }}$ represents the hypothetical outlet temperature for the steady state, one-phase flow for the new pressure boundary condition. $x=1$ represents the steady state.

Figure 8: Stanton number versus Peclet number - computational results for various transient states 


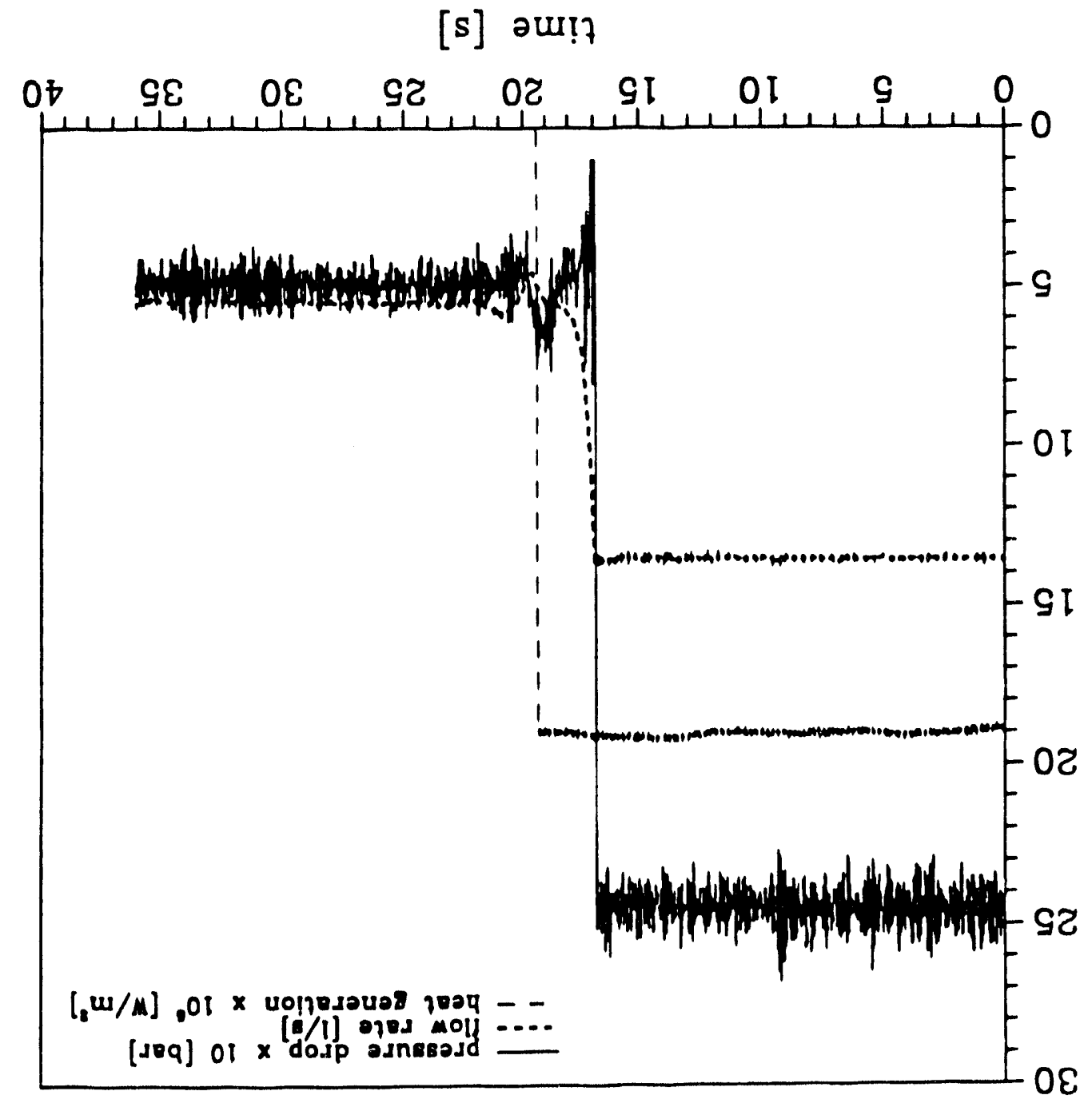




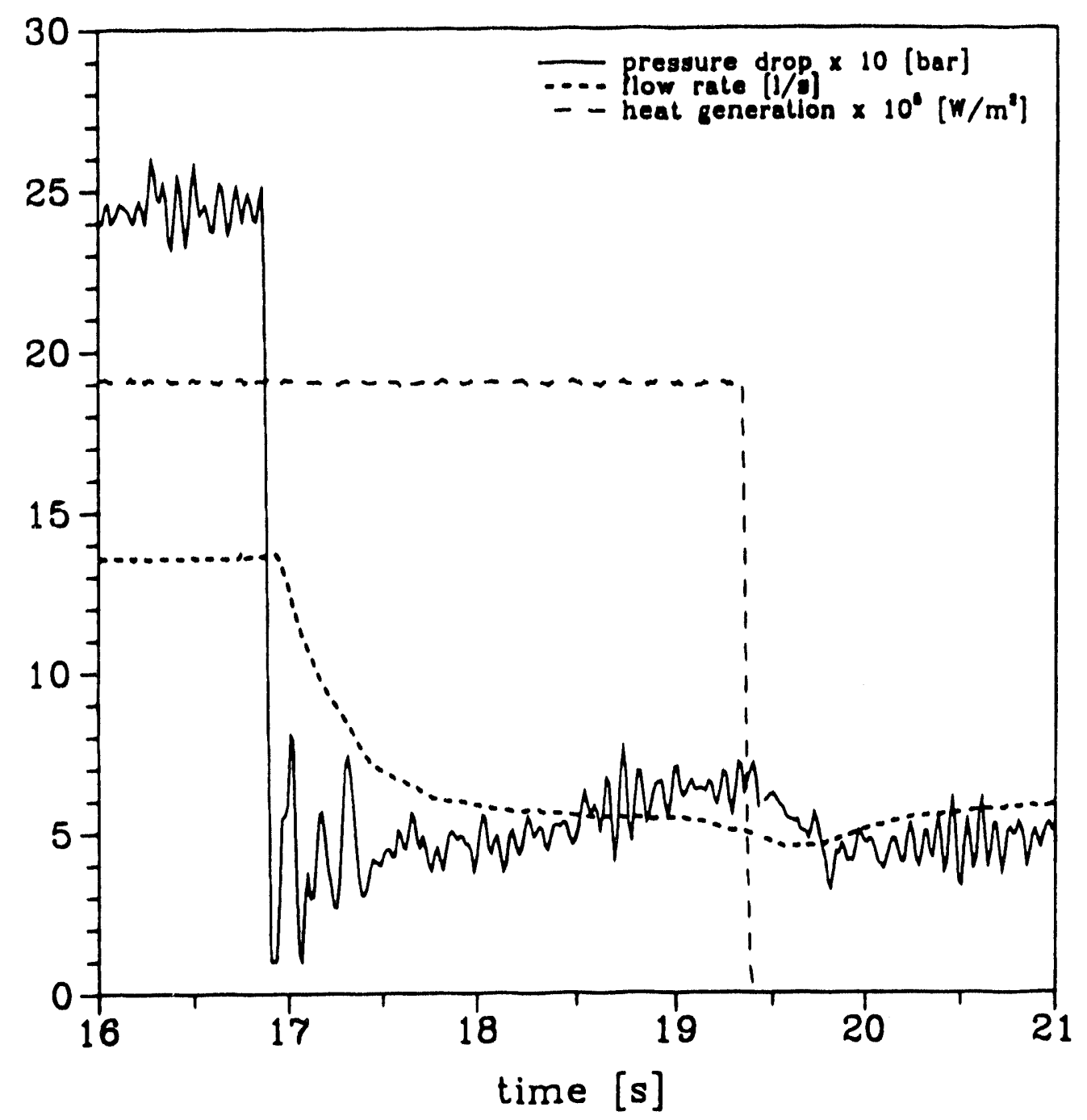

Figure 10: Pressure drop, flow rate and heat generation - experimental results of test $C$ 


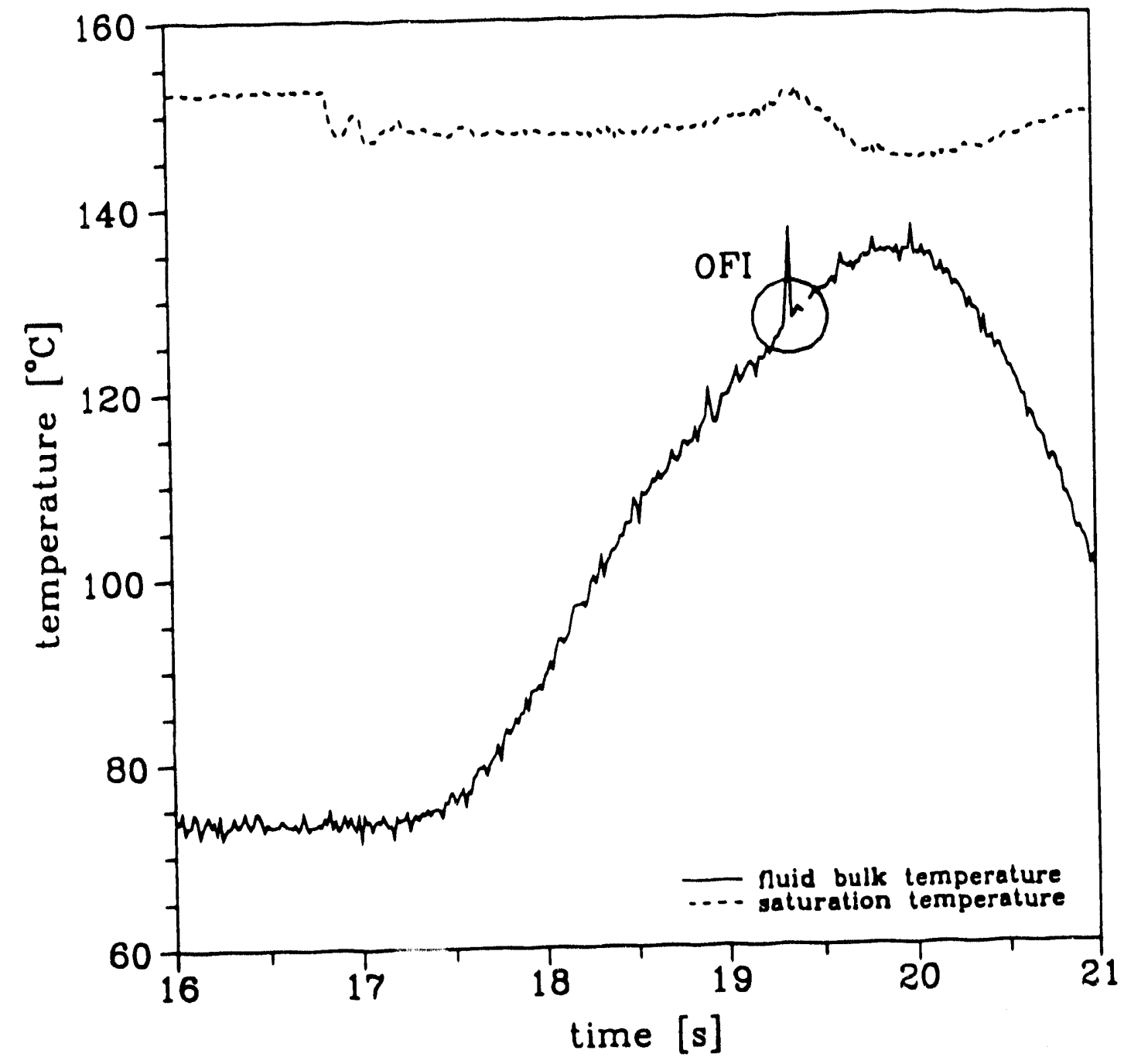

Figure 11: Fluid bulk temperature and saturation temperatue at the outlet - experimental results of test $\mathrm{C}$ 


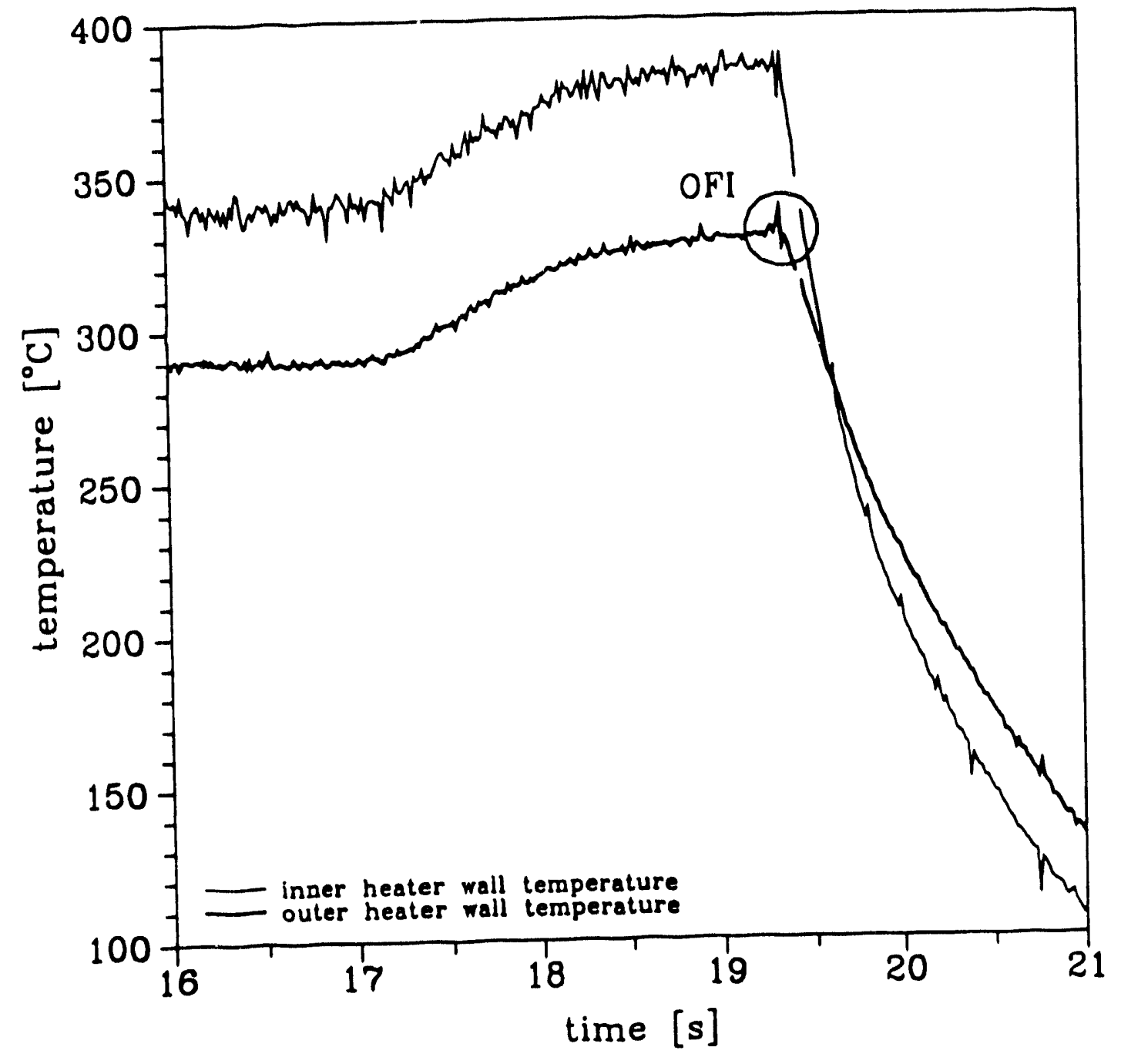

Figure 12: Wall temperatures - experimental results for test C 


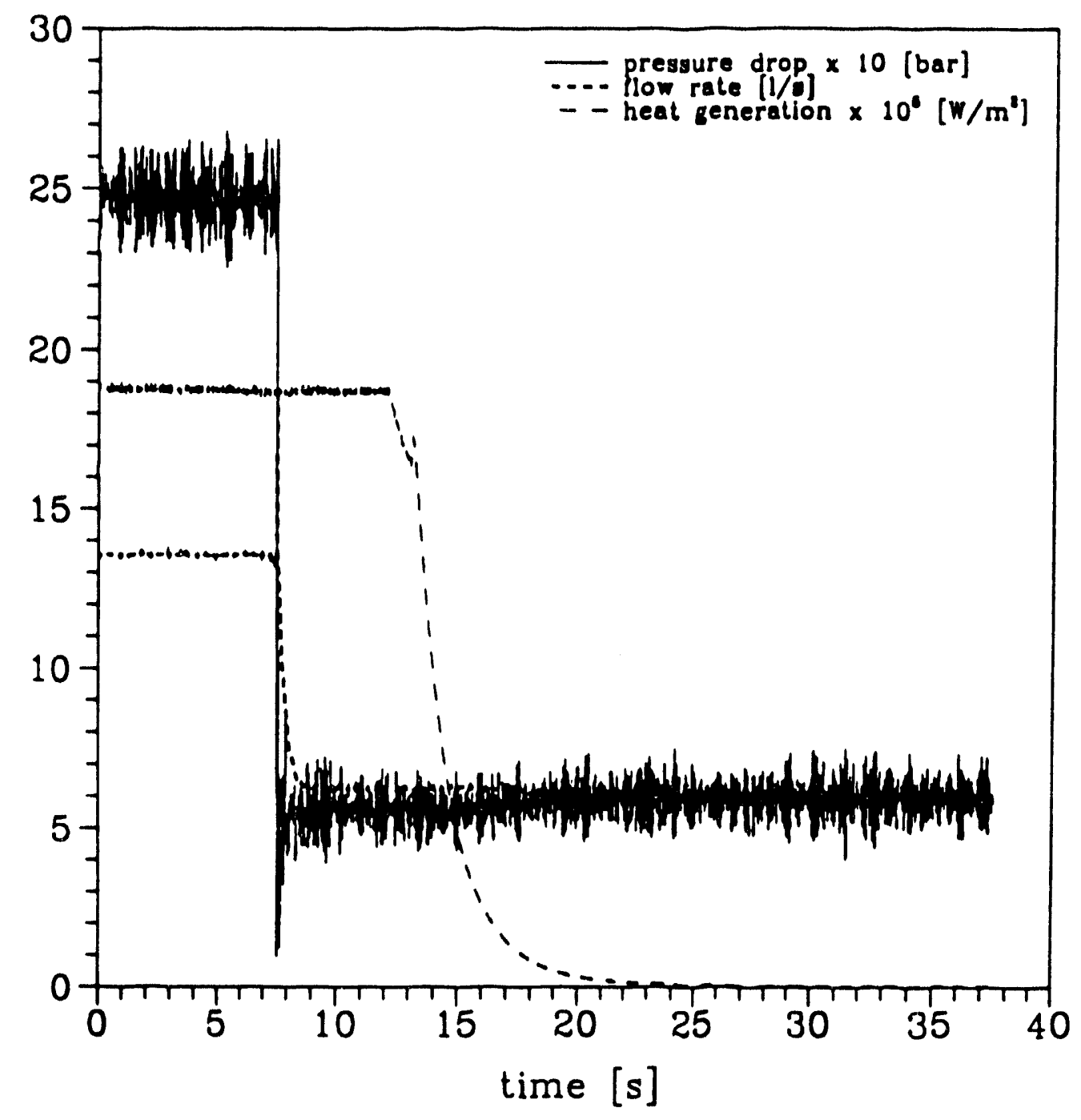

Figure 13: Pressure drop, flow rate and heat generation - experimental results of test $G$ 


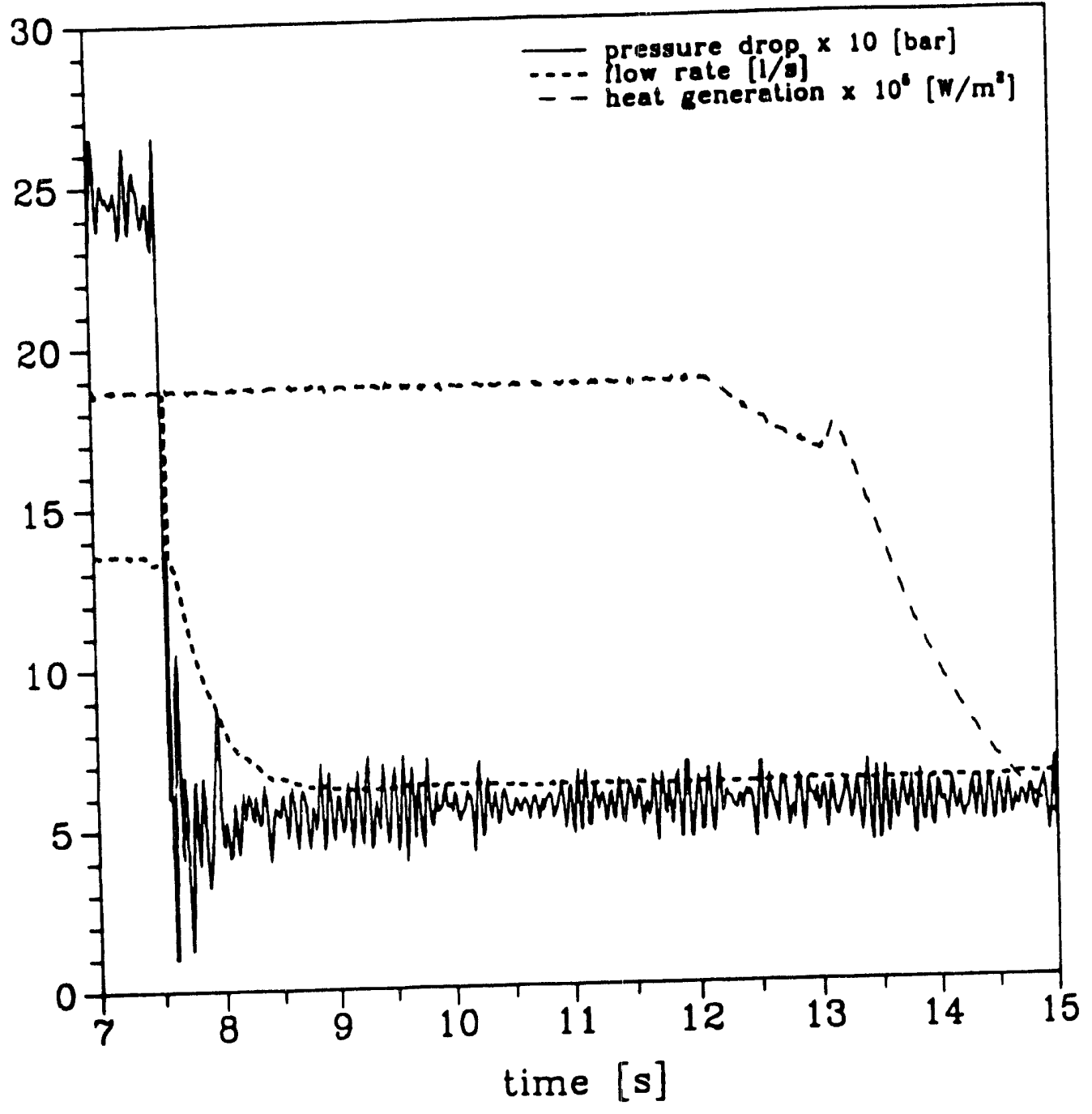

Figure 14: Pressure drop, flow rate and heat generation - experimental results of test $\mathrm{G}$ 


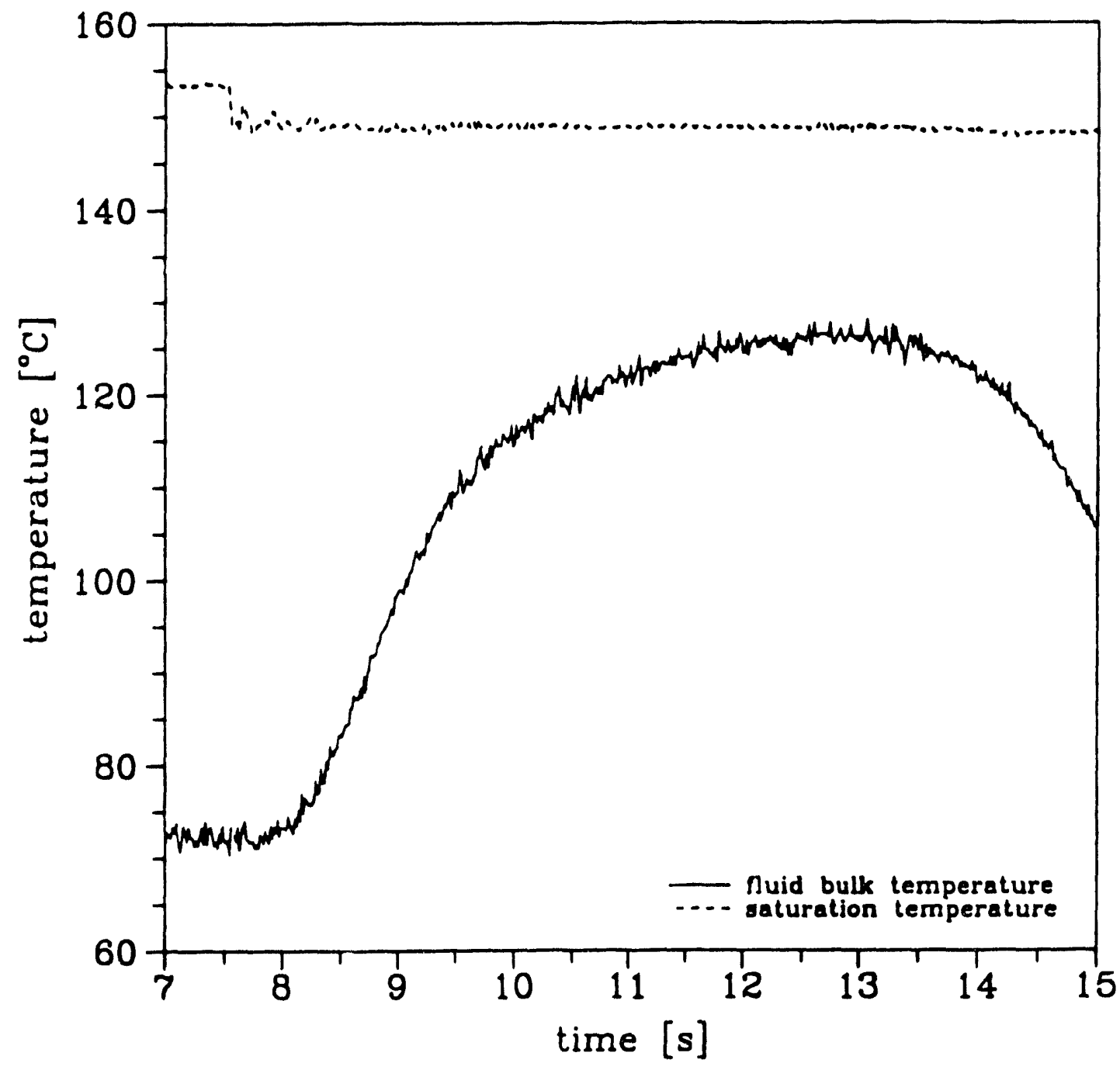

Figure 15: Fluid bulk temperature and saturation temperatue at the outlet - experimental results of test $G$ 


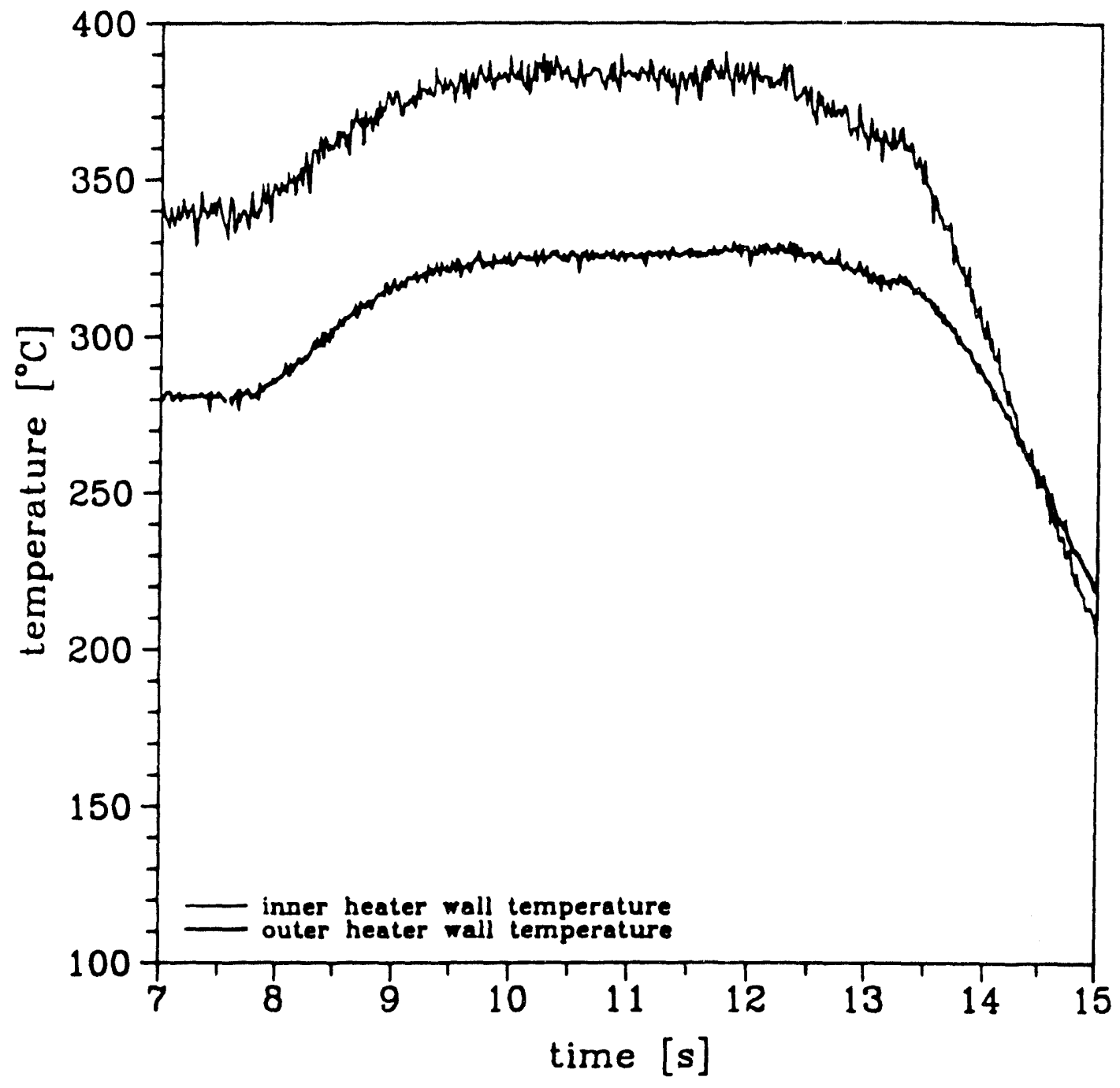

Figure 16: Wall temperatures - experimental results for test G 


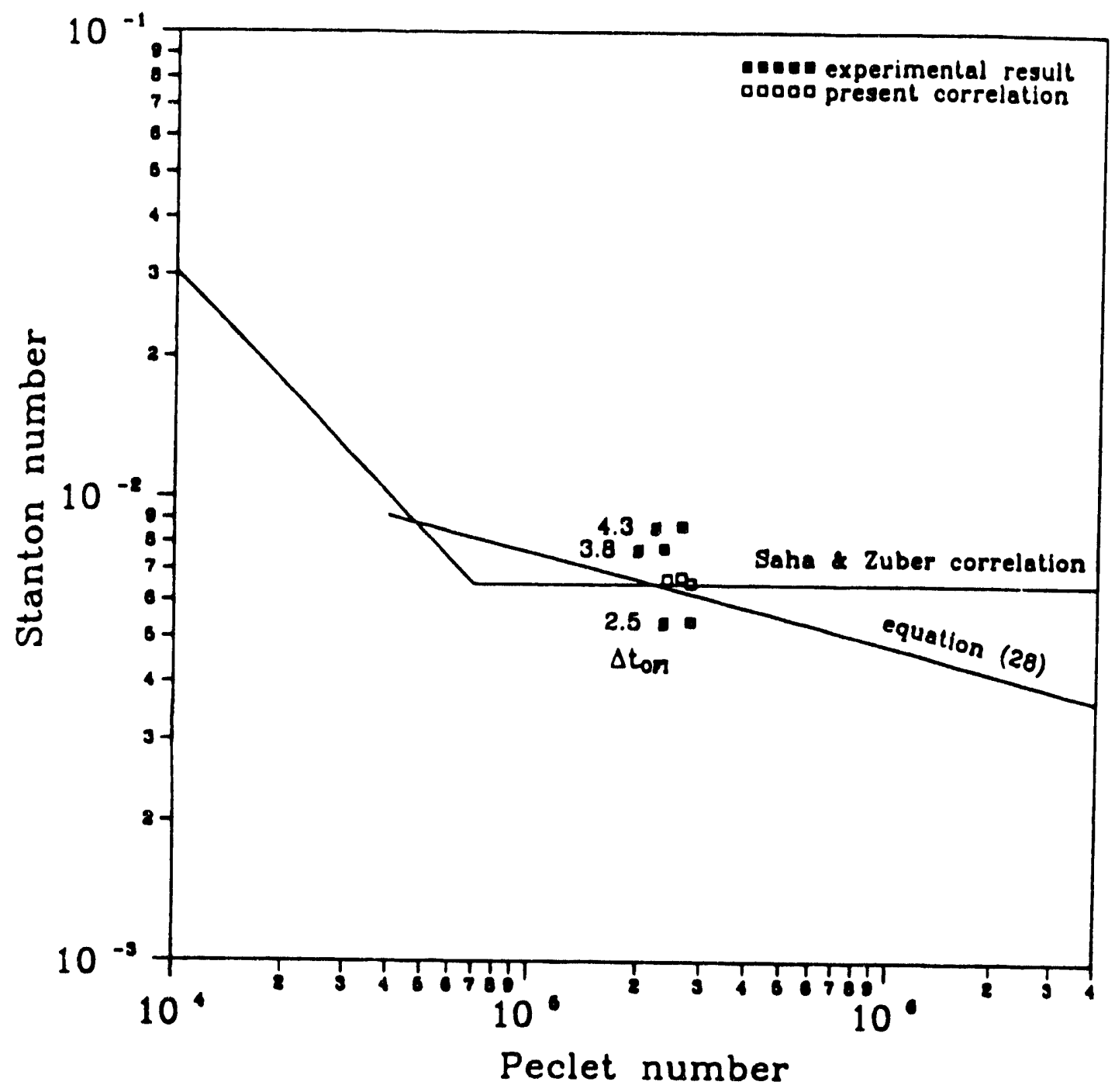

Figure 17: Stanton number versus Peclet number at OFI - tests C, D and F 
(a)

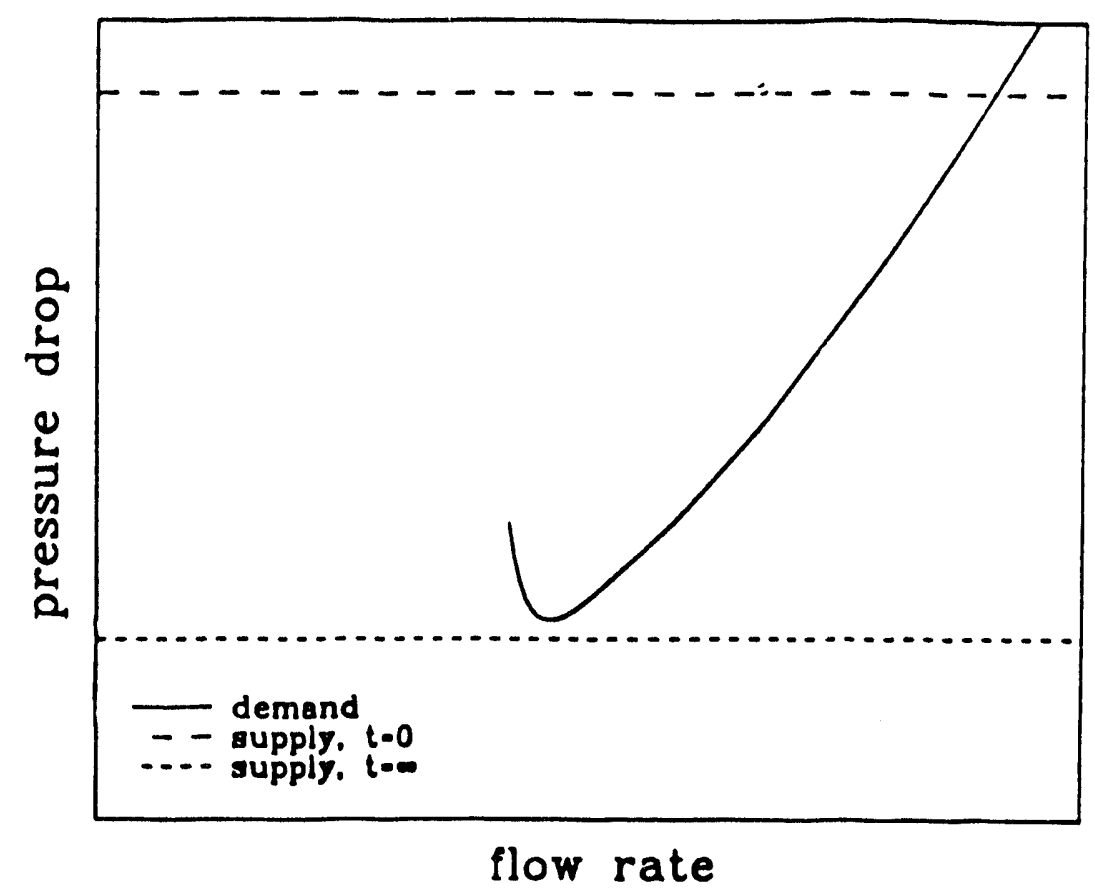

(b)

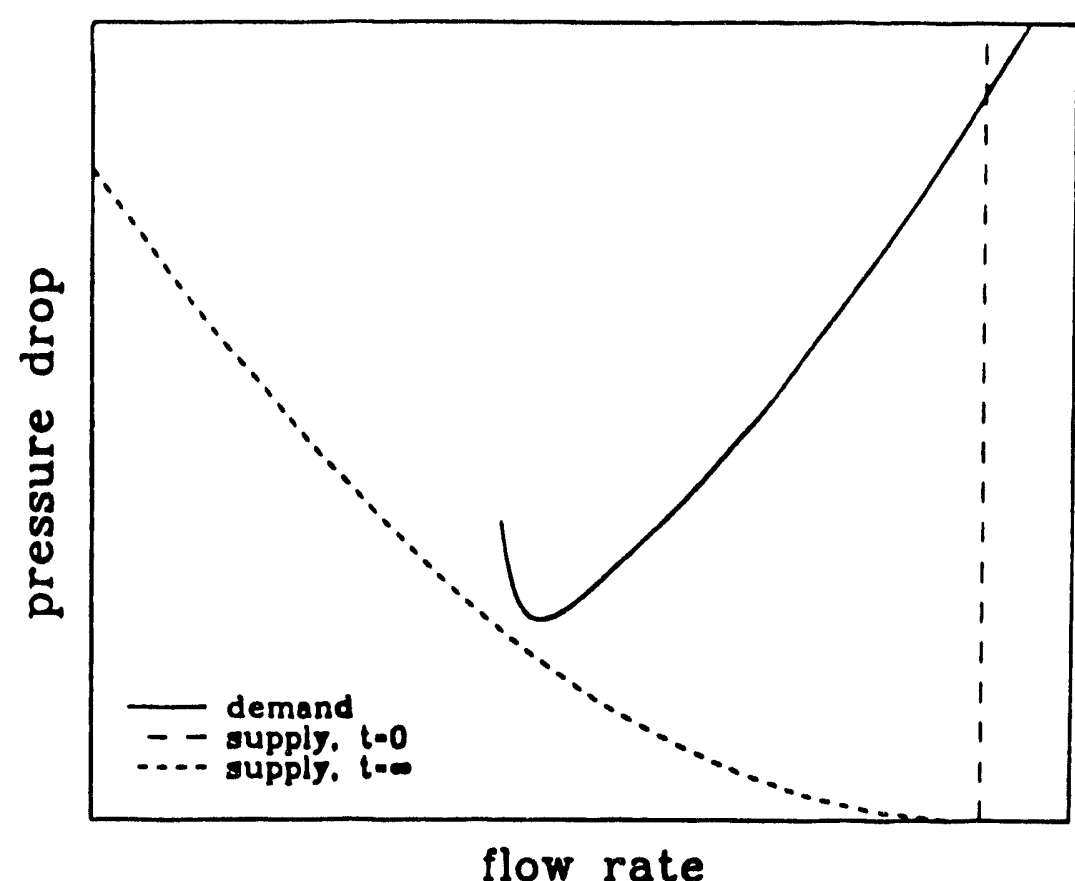

Figure 18: Supply and demand pressure drop profiles: (a) constant pressuredrop assumption, (b) experiment 


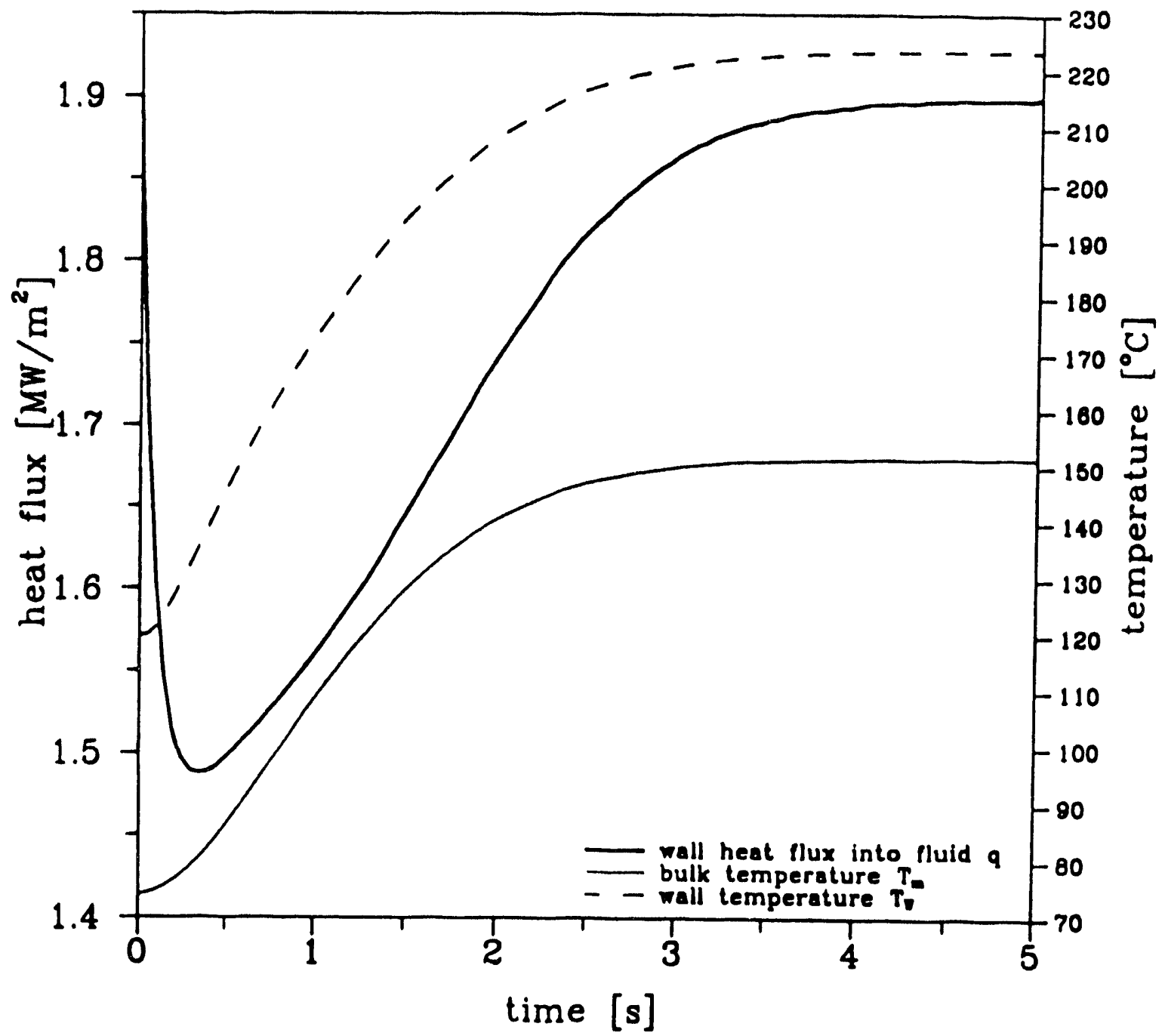

Figure 19: Wall heat flux into fluid, fluid bulk temperature and wall temperature - computational result for test $\mathbf{C}$ 


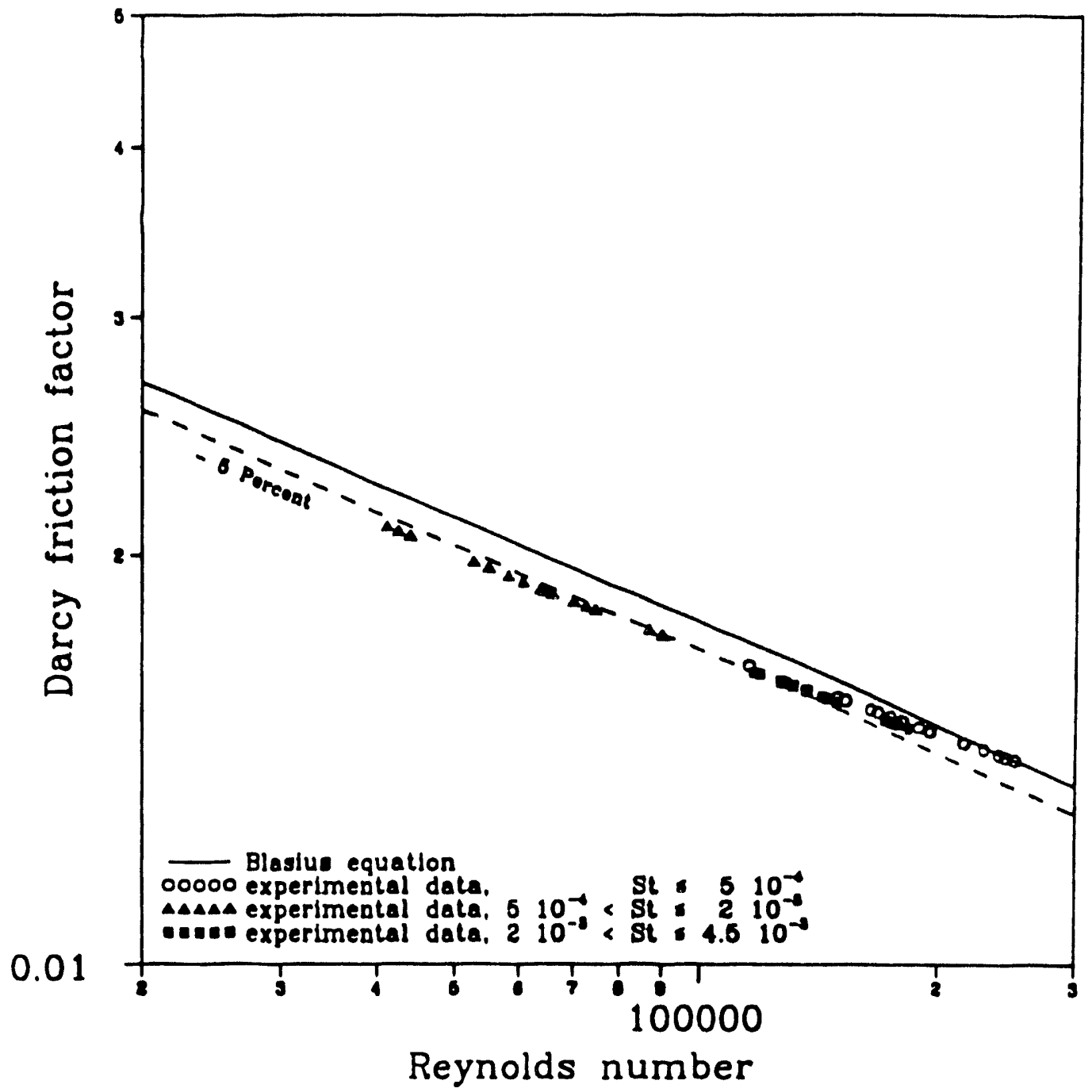

Figure 20: Darcy friction factor - computational result, steady-state 


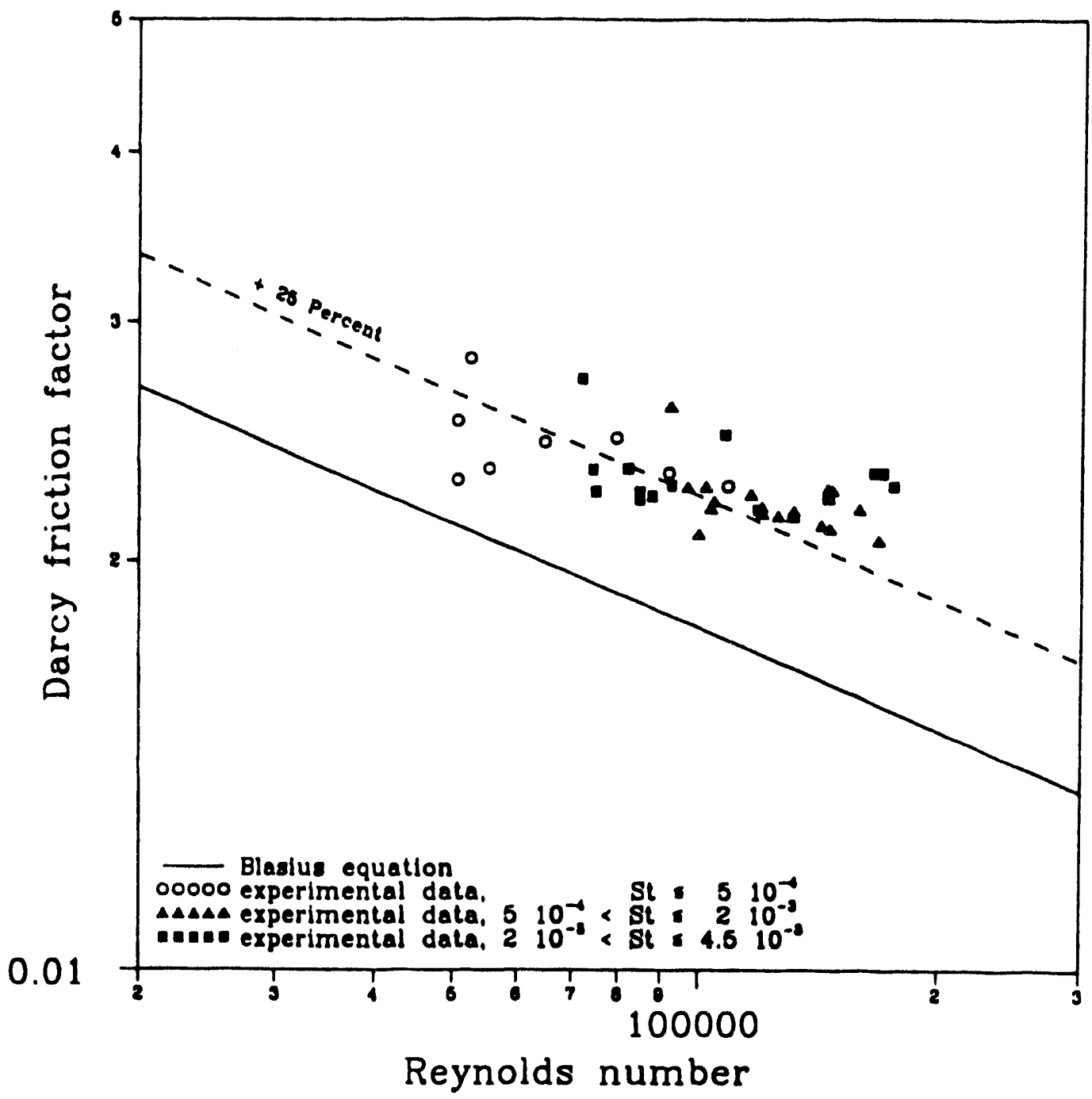

Figure 21: Darcy friction factor - experimental result, steady-state 

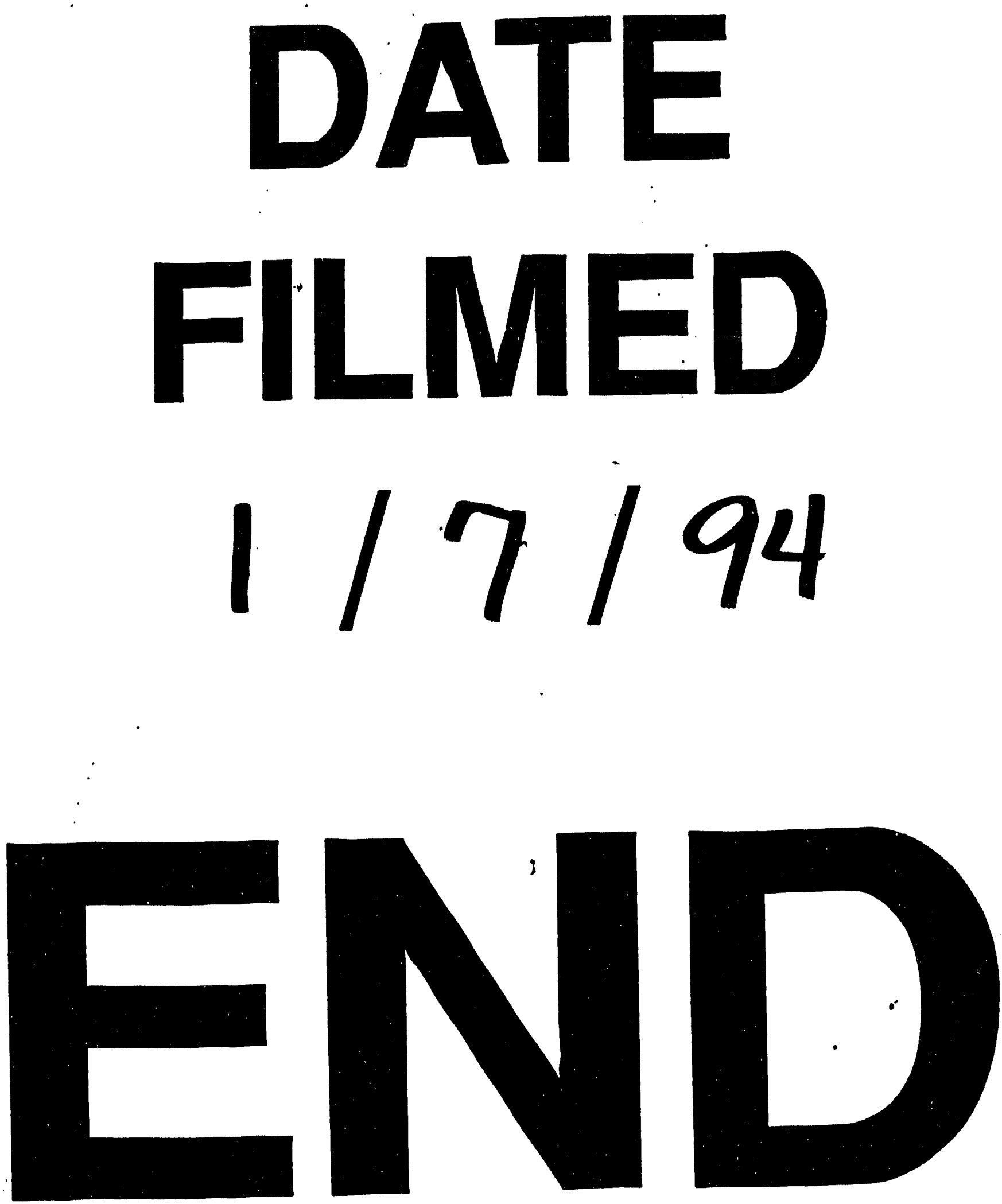


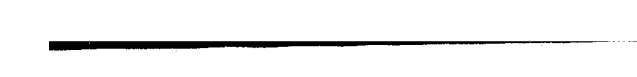

1

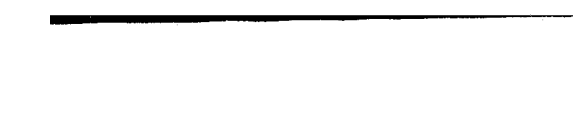

